REVIEW

\title{
The looming tide of nontuberculous mycobacterial infections in Portugal and Brazil
}

\author{
Daniela Nunes-Costa ${ }^{a}$, Susana Alarico ${ }^{a}$, Margareth Pretti Dalcolmo ${ }^{b}$, \\ Margarida Correia-Neves ${ }^{\mathrm{c}, \mathrm{d}}$, Nuno Empadinhas ${ }^{\mathrm{a}, \mathrm{e}, *}$ \\ ${ }^{a}$ CNC - Center for Neuroscience and Cell Biology, University of Coimbra, Coimbra, Portugal \\ ${ }^{\mathrm{b}}$ Reference Center Helio Fraga, Fundação Oswaldo Cruz, FIOCRUZ, MoH, Rio de Janeiro, Brazil \\ c ICVS - Health and Life Sciences Research Institute, University of Minho, Braga, Portugal \\ d ICVS/3B's, PT Government Associate Laboratory, Braga/Guimarães, Portugal \\ e IIIUC - Institute for Interdisciplinary Research, University of Coimbra, Coimbra, Portugal
}

\section{A R T I C L E I N F O}

\section{Article history:}

Received 5 May 2015

Received in revised form

27 August 2015

Accepted 16 September 2015

\section{Keywords:}

Nontuberculous mycobacteria

Emerging infections

Opportunistic pathogens

Mycobacterioses

Portugal

Brazil

\begin{abstract}
S U M M A R Y
Nontuberculous mycobacteria (NTM) are widely disseminated in the environment and an emerging cause of infectious diseases worldwide. Their remarkable natural resistance to disinfectants and antibiotics and an ability to survive under low-nutrient conditions allows NTM to colonize and persist in man-made environments such as household and hospital water distribution systems. This overlap between human and NTM environments afforded new opportunities for human exposure, and for expression of their often neglected and underestimated pathogenic potential. Some risk factors predisposing to NTM disease have been identified and are mainly associated with immune fragilities of the human host. However, infections in apparently immunocompetent persons are also increasingly reported. The purpose of this review is to bring attention to this emerging health problem in Portugal and Brazil and to emphasize the urgent need for increased surveillance and more comprehensive epidemiological data in both countries, where such information is scarce and seriously thwarts the adoption of proper preventive strategies and therapeutic options.
\end{abstract}

(c) 2015 Elsevier Ltd. All rights reserved.

\section{Contents}

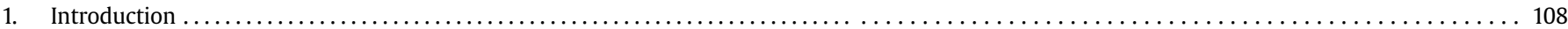

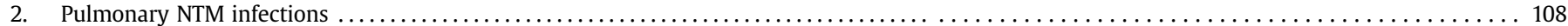

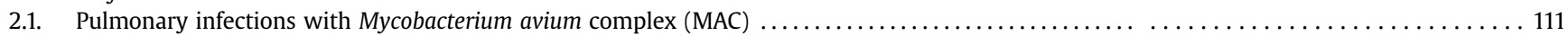

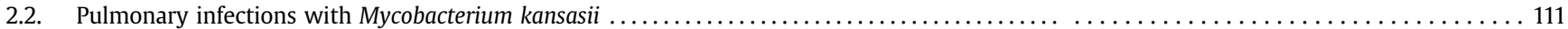

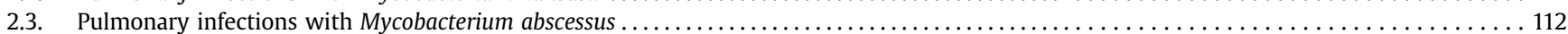

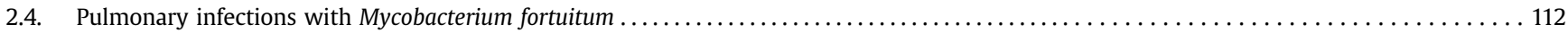

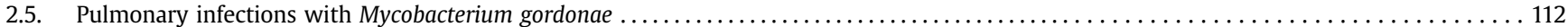

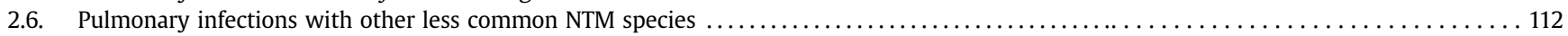

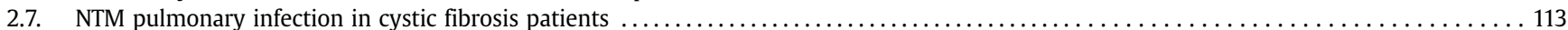

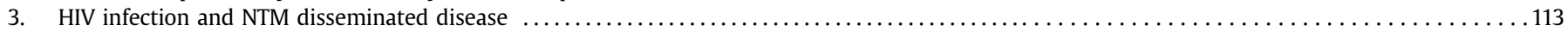

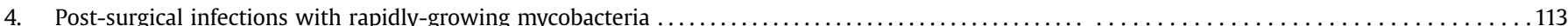

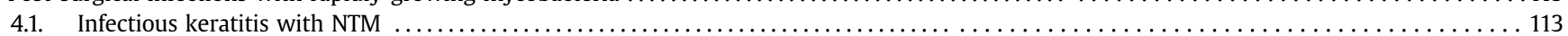

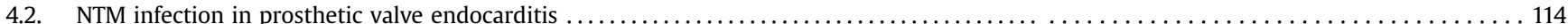

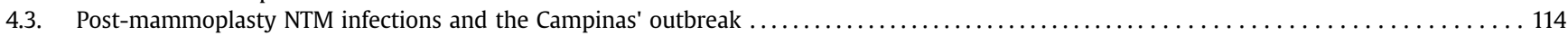

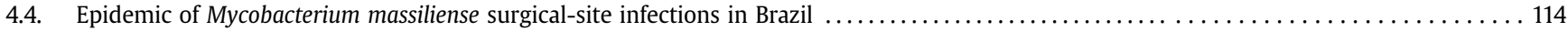

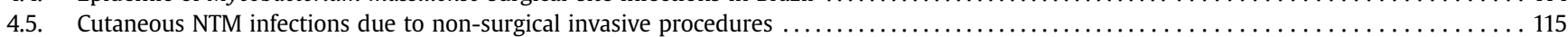

\footnotetext{
* Corresponding author. CNC - Center for Neuroscience and Cell Biology, University of Coimbra, Coimbra, Portugal.
}

E-mail address: numenius@cnc.uc.pt (N. Empadinhas). 


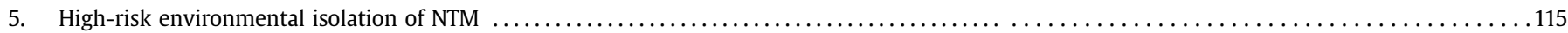

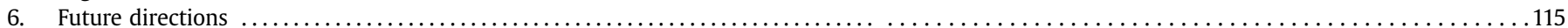

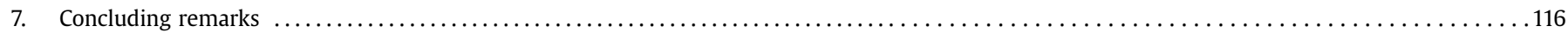

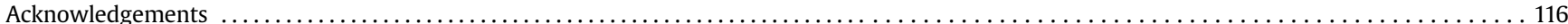

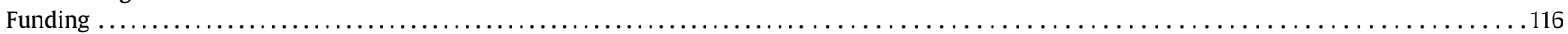

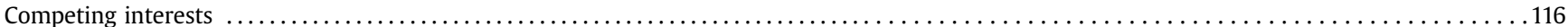

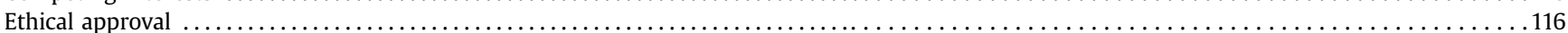

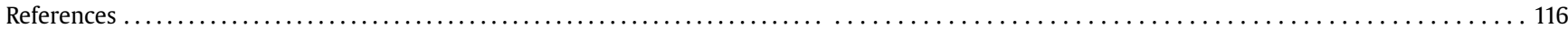

\section{Introduction}

The genus Mycobacterium is notorious for including the pathogens accountable for two of the most ancient diseases known to humankind, leprosy and tuberculosis (TB), responsible for countless deaths and affliction through human history [1,2]. However, since Hansen's discovery of Mycobacterium leprae in 1873 and Koch's discovery of Mycobacterium tuberculosis nine years later, the list of described mycobacterial species has grown and currently counts with 170 species and subspecies (www.bacterio.net/ mycobacterium.html) (Figure 1). These less known and often neglected mycobacteria, collectively called nontuberculous mycobacteria (NTM), are ubiquitous environmental saprophytes and increasingly regarded as opportunistic human pathogens [6]. Although only a few NTM species are familiar to clinicians and commonly associated with human infection, many of the species described over the last two decades are regarded as potentially pathogenic (Figure 1) [7,8]. The success of NTM both as ubiquitous saprophytes and as opportunistic pathogens can in part be explained by their natural resilience to stress conditions such as desiccation, nutrient starvation, extreme temperatures and $\mathrm{pH}$, and antimicrobials resistance $[9,10]$. Along with their biofilm-forming capabilities, these characteristics render NTM particularly wellsuited for the colonization of artificial environments such as chlorinated water supply networks, where they can proliferate and gain advantage over their chlorine-sensitive competitors [9,11,12].

Mycobacteria are traditionally divided into slowly-growing mycobacteria (SGM) and rapidly-growing mycobacteria (RGM) based on growth rate and although historically the species within the SGM group are the ones that have almost always been associated with disease, the significant numbers of nosocomial infections caused by RGM have changed this perception [13]. In fact, convincing evidence indicates that the numbers of NTM infections caused by both SGM and RGM species are rising worldwide although the lack of systematic reporting in most countries still renders it difficult to establish definitive conclusions concerning their true global incidence [14-17]. Several hypotheses have been proposed to explain this rising trend, notably the increasing overlap of human and mycobacterial habitats (e.g., water distribution systems), increased numbers of NTM in drinking water due to changes in water quality and wider adoption of disinfection regimens that promote selection for these organisms, greater physician awareness of NTM as a possible cause of infections leading to more cases being diagnosed and reported, and the greater prevalence of some predisposing factors in the human population [18]. Risk factors for NTM disease that have been identified so far include: (i) lowered immunocompetence due to HIV infection, cancer, chemotherapy, use of immunosuppressive drugs following transplants or ageing-dependent immunosenescence; (ii) underlying lung conditions such as chronic obstructive pulmonary disease, cystic fibrosis, lung damage due to occupational exposure, to smoking, to prior tuberculosis or other lung disease; (iii) genetic factors, namely mutations in the cystic fibrosis transmembrane conductance regulator gene or in the $\alpha$-1antitrypsin gene [19].

In this review, we will focus on the information available about the current status of NTM infections in Portugal and Brazil, two countries for which epidemiological data is still scarce and whose historically high TB burdens [20] have for many years overshadowed the role of NTM in human disease. In 2013, Portugal had a tuberculosis incidence rate of 26 cases per 100,000 population while in Brazil the incidence rate was 46 per 100,000 population [20]. In order to shed light into this emerging health problem, we conducted a survey of the available literature on NTM infections in Portugal and Brazil by searching PubMed, Web of Science, Google Scholar, SciELO and Lilacs databases between December 2014 and February 2015. The keywords mycobacter*, atypical or nontuberculous or non-tuberculous, Portugal or Brazil, infection or outbreak or disease or isolation were used and the search was repeated in Portuguese. Reports in languages other than English or Portuguese and with ambiguous or absent geographical information were excluded, no other exclusion criteria were employed.

\section{Pulmonary NTM infections}

Pulmonary disease is a common manifestation of NTM infection and has been the focus of many recent reviews [21-24]. However, only a few studies have investigated the epidemiology of pulmonary NTM (PNTM) infections in Portugal and Brazil (Table 1) [25-44]. In addition many of these studies have important limitations as will be discussed later in this section. Two of these surveys, conducted in the Greater Lisbon Area, covering the period between 2005 and 2009, independently found NTM to account for approximately $12 \%$ of all isolates from patients diagnosed with mycobacterial disease, leaving the remaining $88 \%$ of the cases to species of the Mycobacterium tuberculosis complex [25,26]. In Brazil, the reported incidence rates differ significantly between different states, periods, and population samples. In the states of Bahia, Pará and Piauí, 8\% of patients presenting symptoms compatible with pulmonary TB were actually found to be infected with NTM $[39,43,44]$. In the state of São Paulo, where most Brazilian studies have been conducted, the percentage of NTM infection among patients suspected of mycobacteriosis has been reported to be around $20 \%[32,33,37,34]$ and in the state of Rondônia one study also found a similar result [41]. Agertt and coworkers reported 33\% of NTM in Rio Grande do Sul but the inclusion of non-clinically relevant samples of both pulmonary and extrapulmonary origin probably led to an overestimation and does not reflect the true incidence of PNTM disease [42].

These results illustrate the relevance of PNTM infections as a public health problem in Portugal and Brazil, but because PNTM disease cases are not of mandatory notification, the true incidence in both countries remains indeterminate due to lack of more comprehensive data. Even in countries with a high incidence of TB, it is important to be aware that a significant proportion of mycobacterial pulmonary disease cases are in fact caused by NTM, 

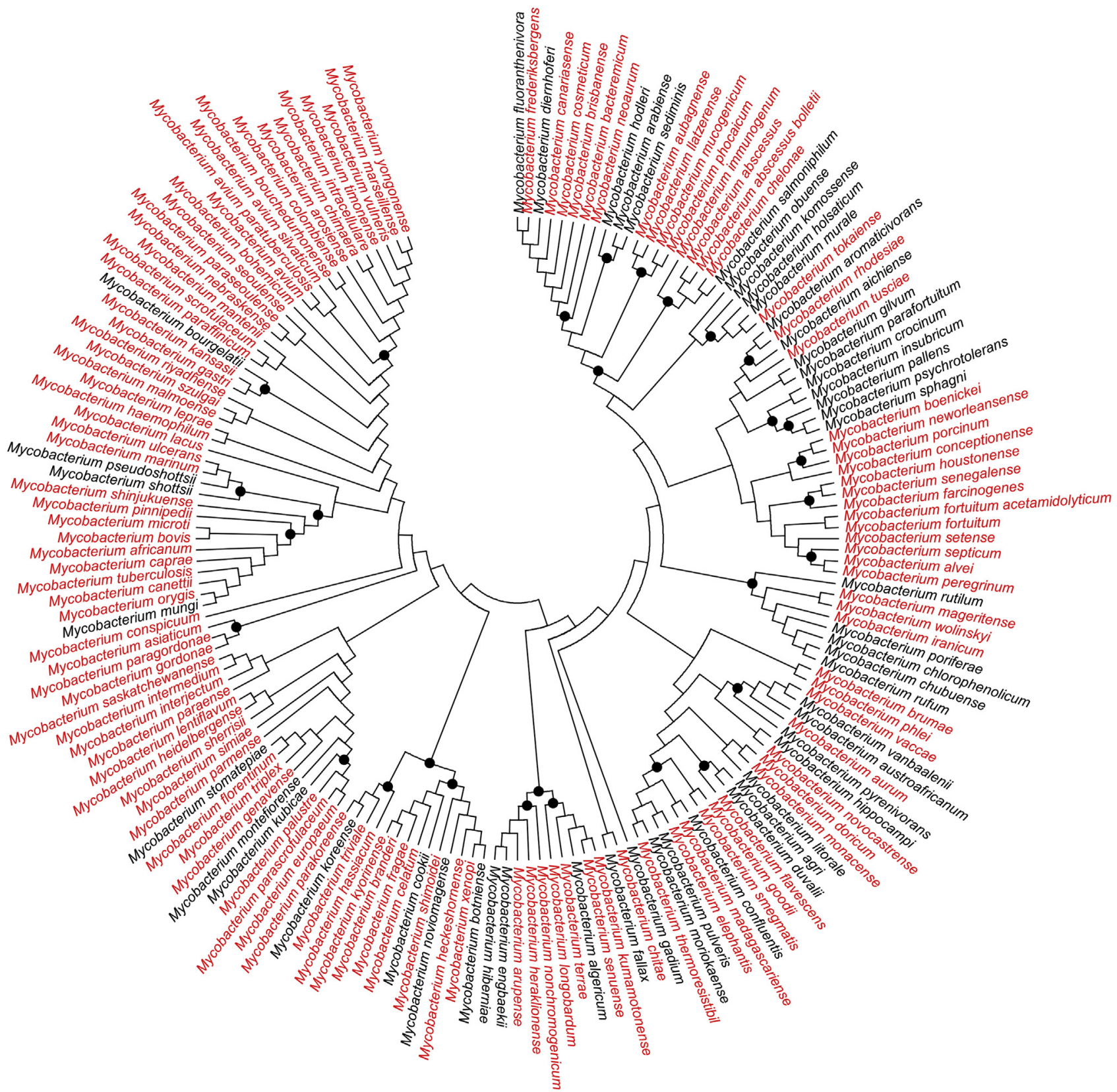

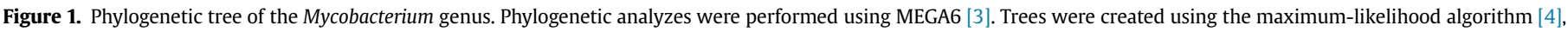

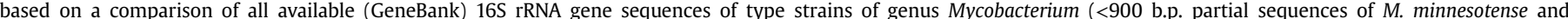

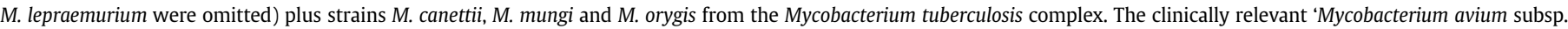

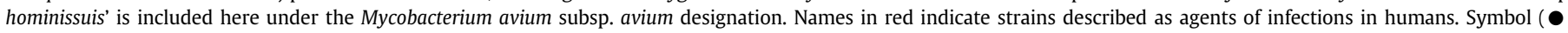

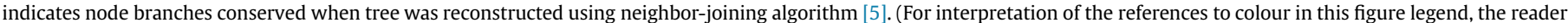
is referred to the web version of this article.)

especially since many species are resistant to first-line anti-TB drugs and regimens (isoniazid, rifampicin, pyrazinamide, and ethambutol) [45]. As an example, standard therapy for the Mycobacterium avium complex pulmonary disease is macrolide-based, requiring the combination of clarithromycin or azithromycin with ethambutol and a rifamycin, and in some cases an aminoglycoside is also recommended [46]. Although less reliably, macrolides are also generally recommended against Mycobacterium abscessus pulmonary disease, combined with one or more parenteral agents between amikacin, cefoxitin and imipenem [47]. As these examples illustrate, failure to identify the infectious agent to the species level may lead to inappropriate antibiotic regimens with consequent therapeutic failures and possibly fostering the emergence of drug resistance trends $[26,38,48,49]$.

It should be noted that NTM isolation from patients with symptoms of lung infectious disease does not in itself mean that the mycobacteria isolated are the source of the disease, as many mycobacteria are known to transiently or persistently colonize patients with an underlying lung condition without necessarily contributing to disease progression. Thus, the American Thoracic 
Table 1

Summary of the characteristics and results of the studies concerning pulmonary nontuberculous mycobacterial (NTM) infections in Portugal and Brazil included in the present review.

Reference

\begin{tabular}{|c|c|c|c|c|c|c|c|}
\hline $\begin{array}{l}\text { Geographic } \\
\text { range }\end{array}$ & Study period & Target population/Study characteristics & $\begin{array}{l}\text { NTM frequency among total } \\
\text { mycobacterial isolates (\%) }\end{array}$ & $\begin{array}{l}\text { No. NTM } \\
\text { isolates }\end{array}$ & Most common species (frequency) & Less common species & Reference \\
\hline \multirow[t]{2}{*}{$\begin{array}{l}\text { Lisbon, } \\
\quad \text { Portugal }\end{array}$} & 2008-2009 & $\begin{array}{l}\text { HIV-negative patients with lung } \\
\text { infection/no confirmation of NTM } \\
\text { infection after isolation }\end{array}$ & 11,4 & 58 & $\begin{array}{l}\text { M. avium complex ( } 22 \%) \text {, M. fortuitum } \\
\text { (14\%), M. gordonae (12\%), M. kansasii } \\
(10 \%) \text {, M. chelonae ( } 9 \%)\end{array}$ & $\begin{array}{l}\text { M. peregrinum, M. abscessus, M. szulgai, } \\
\text { M. triplex, M. mucogenicum, M. } \\
\text { lentiflavum, M. simiae }\end{array}$ & [25] \\
\hline & 2005-2007 & $\begin{array}{l}\text { Patients with presumptive active } \\
\text { mycobacteriosis/no confirmation of } \\
\text { NTM infection after isolation }\end{array}$ & 12,6 & 149 & $\begin{array}{l}\text { M. avium complex ( } 34 \%) \text {, M. gordonae } \\
\text { (15\%), M. fortuitum (9\%), M. kansasii } \\
\text { (9\%), M. chelonae (7\%), M. xenopi (6\%) }\end{array}$ & $\begin{array}{l}\text { M. peregrinum, M. abscessus, } M \text {. } \\
\text { mucogenicum, M. scrofulaceum, } M \text {. } \\
\text { malmoense, M. simiae, } \text { M. lentiflavum, M. } \\
\text { heckeshornense, } \text { M. celatum }\end{array}$ & [26] \\
\hline \multirow[t]{7}{*}{$\begin{array}{l}\text { Northern } \\
\text { Portugal }\end{array}$} & 2008-2012 & $\begin{array}{l}\text { Patients with respiratory sample } \\
\text { positive for NTM/confirmation of NTM } \\
\text { infection }\end{array}$ & NA & 378 & $\begin{array}{l}\text { M. avium complex (63\%), M. gordonae } \\
\text { (11\%), M. peregrinum (9\%), M. chelonae } \\
\text { (7\%), M. kansasii (3\%), M. abscessus (3\%) }\end{array}$ & M. scrofulaceum and others & [27] \\
\hline & & $\begin{array}{l}\text { Subset of confirmed PNTM disease } \\
\text { cases }\end{array}$ & & 68 & $\begin{array}{l}\text { M. avium complex (94\%), M. kansasii } \\
(3 \%), \text { M. xenopi }(3 \%)\end{array}$ & M. scrofulaceum and M. abscessus & \\
\hline & 2005-2011 & Patients with confirmed PNTM disease & NA & 11 & M. avium complex (55\%) & $\begin{array}{l}\text { M. kansasii, M. gordonae, M. fortuitum, } \\
\text { M. peregrinum, M. scrofulaceum }\end{array}$ & [28] \\
\hline & $2007-2010$ & $\begin{array}{l}\text { Patients with respiratory sample } \\
\text { positive for NTM/confirmation of NTM } \\
\text { infection }\end{array}$ & NA & 108 & $\begin{array}{l}\text { M. avium complex ( } 40 \%) \text {, M. gordonae } \\
(34 \%)\end{array}$ & Others & [29] \\
\hline & & $\begin{array}{l}\text { Subset of confirmed PNTM disease } \\
\text { cases }\end{array}$ & & 23 & $\begin{array}{l}\text { M. avium complex }(73 \%), \text { M. kansasii } \\
\text { (9\%), M. gordonae (9\%), M. xenopi (9\%), } \\
\text { M. genavense }(9 \%)\end{array}$ & - & \\
\hline & 1997-2004 & $\begin{array}{l}\text { HIV-negative patients with respiratory } \\
\text { sample positive for NTM/confirmation } \\
\text { of NTM infection }\end{array}$ & NA & 102 & $\begin{array}{l}\text { M. avium complex ( } 47 \%) \text {, M. fortuitum } \\
(21 \%) \text {, M. gordonae (19\%), M. kansasii } \\
\text { (7\%), M. chelonae ( } 2 \%) \text {, M. peregrinum } \\
(2 \%)\end{array}$ & M. abscessus, M. scrofulaceum, M. terrae & [30] \\
\hline & & $\begin{array}{l}\text { Subset of confirmed PNTM disease } \\
\text { cases }\end{array}$ & & 16 & $\begin{array}{l}\text { M. avium complex ( } 75 \%) \text {, M. kansasii } \\
\text { (13\%), M. fortuitum (6\%), M. abscessus } \\
(6 \%)\end{array}$ & - & \\
\hline \multirow[t]{2}{*}{$\begin{array}{l}\text { Multistate, } \\
\text { Brazil }\end{array}$} & 1994-1999 & $\begin{array}{l}\text { Patients with presumptive } \\
\text { mycobacteriosis/confirmation of NTM } \\
\text { infection }\end{array}$ & NA & 431 & $\begin{array}{l}\text { M. avium complex (38\%), M. kansasii } \\
(14 \%) \text {, M. fortuitum (14\%), M. abscessus } \\
(7 \%), \text { M. terrae (4\%) }\end{array}$ & $\begin{array}{l}\text { M. scrofulaceum, M. gordonae, } M \text {. } \\
\text { peregrinum, M. szulgai, M. chelonae, M. } \\
\text { flavescens, M. asiaticum, M. } \\
\text { nonchromogenicum, M. mucogenicum, } \\
\text { M. malmoense, M. marinum }\end{array}$ & [31] \\
\hline & & $\begin{array}{l}\text { Subset of confirmed PNTM disease } \\
\text { cases }\end{array}$ & NA & 64 & $\begin{array}{l}\text { M. avium complex (53\%), M. kansasii } \\
\text { (20\%), M. fortuitum, M. abscessus (6\%), } \\
\text { M. chelonae (6\%), M. scrofulaceum (4\%), } \\
\text { M. szulgai (3\%) }\end{array}$ & - & \\
\hline \multirow[t]{6}{*}{$\begin{array}{l}\text { São Paulo } \\
\text { state, Brazil }\end{array}$} & 2009-2010 & $\begin{array}{l}\text { Patients with clinical sample positive } \\
\text { for NTM/no confirmation of NTM } \\
\text { infection }\end{array}$ & 23 & 84 & $\begin{array}{l}\text { M. avium complex ( } 45 \%), \text { M. fortuitum } \\
\text { (10\%), M. abscessus (10\%), M. kansasii } \\
\text { (8\%), M. gordonae (6\%), M. flavescens } \\
(4 \%)\end{array}$ & $\begin{array}{l}\text { M. xenopi, M. szulgai, } \text { M. parmense, } M \text {. } \\
\text { chelonae, M. lentiflavum, } \text { M. simiae, } M \text {. } \\
\text { sherrisii, M. mucogenicum, M. kubicae, } \text { M. } \\
\text { alvei }\end{array}$ & [32] \\
\hline & $2000-2004$ & $\begin{array}{l}\text { HIV-positive patients with symptoms of } \\
\text { pulmonary tuberculosis }\end{array}$ & 24,2 & 42 & $\begin{array}{l}\text { M. avium complex (14\%), M. fortuitum } \\
\text { (14\%), M. kansasii (12\%) }\end{array}$ & $\begin{array}{l}\text { M. chelonae, M. shimodei, M. triviale, M. } \\
\text { terrae, M. peregrinum }\end{array}$ & [33] \\
\hline & 1996-2005 & $\begin{array}{l}\text { Patients with respiratory sample } \\
\text { positive for NTM/confirmation of NTM } \\
\text { infection }\end{array}$ & 24,4 & 271 & $\begin{array}{l}\text { M. avium complex ( } 56 \%) \text {, M. gordonae } \\
\text { (12\%), M. fortuitum ( } 8 \%) \text {, M. terrae (3\%), } \\
\text { M. chelonae (3\%) }\end{array}$ & $\begin{array}{l}\text { M. kansasii, M. abscessus, } M . \\
\text { scrofulaceum, M. peregrinum, } M . \\
\text { shimodei, } \text { M. malmoense, } \text { M. neoaurum, } \\
\text { M. flavescens, M. interjectum }\end{array}$ & [34] \\
\hline & & $\begin{array}{l}\text { Subset of confirmed PNTM disease } \\
\text { cases }\end{array}$ & & 35 & $\begin{array}{l}\text { M. avium complex (63\%), M. fortuitum } \\
\text { (11\%), M. gordonae (9\%), M. chelonae } \\
(6 \%)\end{array}$ & M. kansasii, M. abscessus, M. malmoense & \\
\hline & $2000-2005$ & $\begin{array}{l}\text { Patients with symptoms of pulmonary } \\
\text { tuberculosis/confirmation of NTM } \\
\text { infection }\end{array}$ & NA & 194 & $\begin{array}{l}\text { M. kansasii }(34 \%) \text {, M. avium complex } \\
\text { (17\%), M. fortuitum (13\%), M. peregrinum } \\
\text { (2\%), M. gordonae ( } 2 \%)\end{array}$ & $\begin{array}{l}\text { M. nonchromogenicum, M. chelonae, } M \text {. } \\
\text { terrae, M. triviale, M. flavescens, } M \text {. } \\
\text { bohemicum, M. shimodei, M. lentiflavum }\end{array}$ & [35] \\
\hline & 1991-1997 & $\begin{array}{l}\text { Patients with respiratory sample } \\
\text { positive for NTM/no confirmation of } \\
\text { NTM infection }\end{array}$ & NA & 600 & $\begin{array}{l}\text { M. avium complex (51\%), M. kansasii } \\
(21 \%) \text {, M. gordonae (12\%), M. fortuitum } \\
(5 \%) \text {, M. terrae (3\%) }\end{array}$ & M. chelonae, M. xenopi, M. szulgai & [36] \\
\hline
\end{tabular}




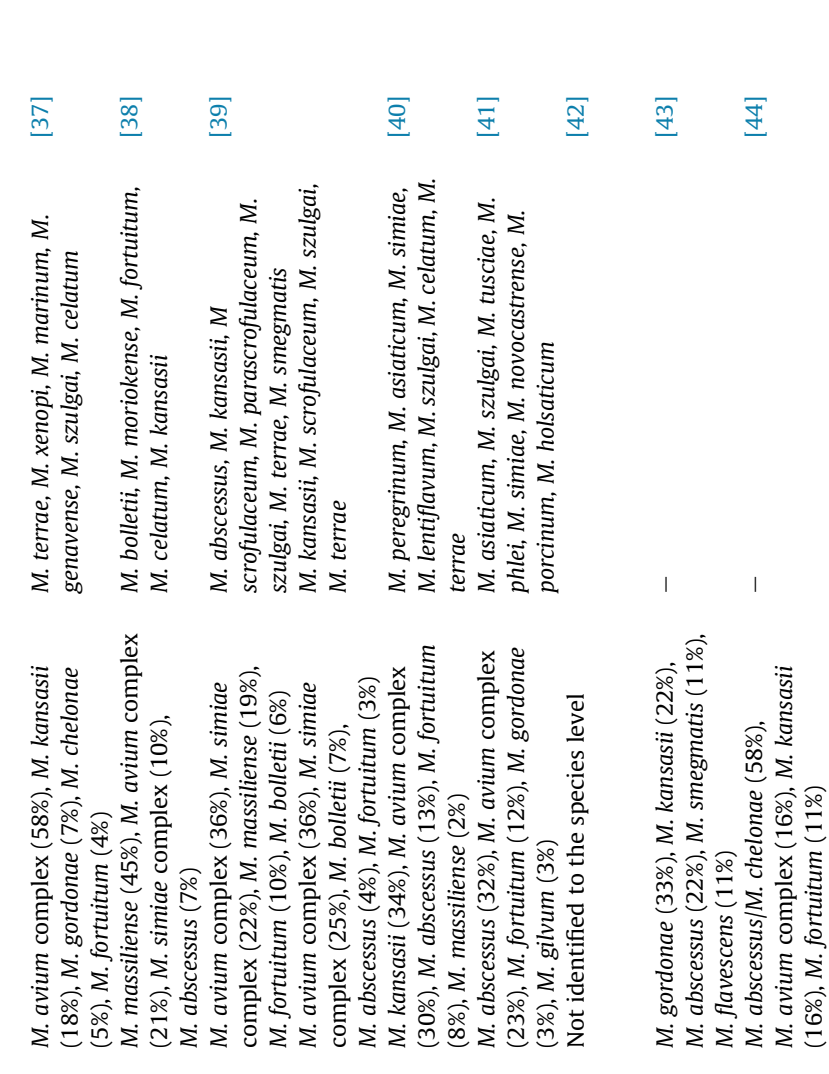

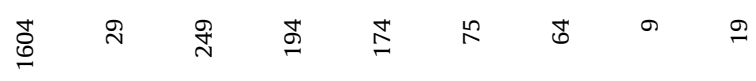

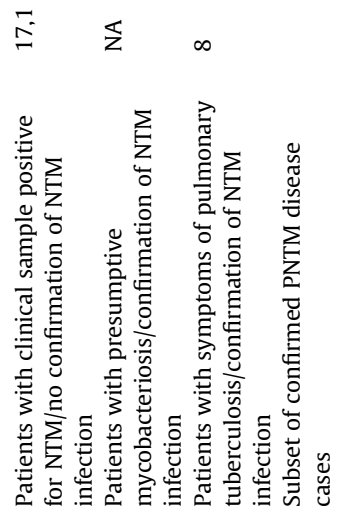

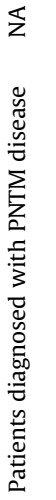

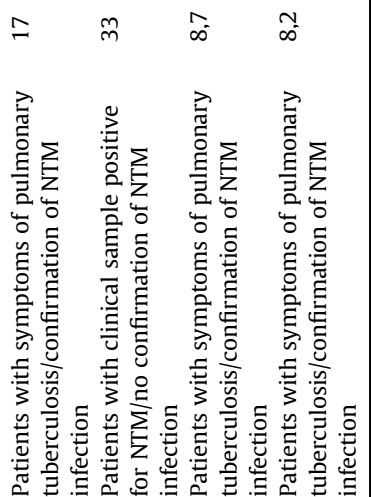

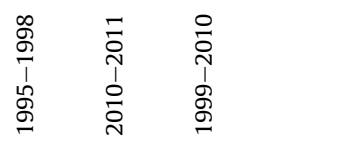

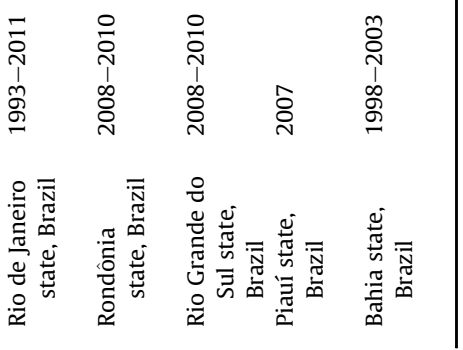

Society and the Infectious Diseases Society of America (ATS/IDSA) have issued diagnostic criteria to aid diagnosis of PNTM disease cases and distinguish them from simple colonization [45]. Clinical, radiographic and microbiological evidence are needed, as well as exclusion of other disorders such as TB. Unfortunately, for a great proportion of the published studies on PNTM these criteria and clinical relevance of NTM isolation were not assessed. However, some of these studies were relevant for the present review and were likewise included, although special care was taken to provide the accurate information to the reader. Furthermore, the population analyzed and type of clinical specimens included in each study varies widely, rendering comparisons between the few available studies difficult to draw. Nevertheless, some patterns emerge from a careful analysis of the literature, with some species being particularly prominent. Table 2 ranks the species isolated in Portugal and Brazil according to their frequency of isolation across all the studies included in this review, revealing $M$. avium complex, Mycobacterium kansasii, Mycobacterium gordonae, Mycobacterium fortuitum and $M$. abscessus as the most consistently frequent species when both countries are considered. Next, the NTM most frequently isolated from respiratory samples in Portugal and Brazil are presented and their clinical relevance briefly discussed.

\subsection{Pulmonary infections with Mycobacterium avium complex $(M A C)$}

The M. avium complex harbors the species Mycobacterium avium (which itself includes the subspecies M. avium subsp. avium, 'M. avium subsp. hominissuis', M. avium subsp. paratuberculosis and M. avium subsp. silvaticum [50,51]), Mycobacterium intracellulare, Mycobacterium chimaera, Mycobacterium colombiense, Mycobacterium arosiense, Mycobacterium vulneris, Mycobacterium marseillense, Mycobacterium bouchedurhonense and Mycobacterium timonense (Figure 1). In humans, 'M. avium subsp. hominissuis', $M$. intracellulare and $M$. chimaera seem to be the most relevant opportunistic pathogens of the complex. These are the most frequently isolated mycobacteria in Portugal and Brazil, even though most studies do no not attempt to distinguish between the different species and subspecies of MAC. The frequency of MAC among mycobacterial isolates shows a lot of variation between studies, but is often around 50\%. In Portugal, it seems to be more common in the Northern region, with frequencies ranging from $55 \%$ to $75 \%$ of all NTM isolates [27-30], than in Lisbon, where it has been reported to be below $35 \%$ [25,26], although data are limited. One consistent finding across studies that attempt to distinguish disease cases within the sampled population is that MAC isolation, unlike isolation of other species such as M. gordonae, is significantly associated with NTM disease [29,31,34]. This highlights the clinical relevance of this documented and often deadly human pathogen [52]. MAC lung disease is known for its high treatment failure rates and poor outcome, mainly due to its relative resistance to chemotherapy and to a frustrating lack of correlation between in vitro susceptibility results and in vivo clinical responses to tested antibiotics [21]. This lack of correlation is also observed for other NTM species and has been attributed to innate resistance mechanisms, differences in the metabolic state of mycobacteria in vitro and in vivo, and to laboratory technical difficulties with drug susceptibility assays $[46,47]$.

\subsection{Pulmonary infections with Mycobacterium kansasii}

Mycobacterium kansasii is the second NTM species most frequently isolated from respiratory samples in Brazil. In two studies conducted in São Paulo and Rio de Janeiro it was actually 
Table 2

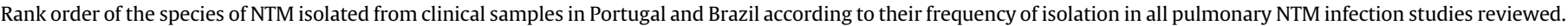
A total of 806 NTM isolates in Portugal and 3781 in Brazil were considered.

\begin{tabular}{|c|c|c|c|}
\hline Portugal & & Brazil & \\
\hline M. avium complex & $49 \%$ & M. avium complex & $48 \%$ \\
\hline M. gordonae & $16 \%$ & M. kansasii & $17 \%$ \\
\hline M. fortuitum, M. peregrinum & $6 \%$ & M. fortuitum & $7 \%$ \\
\hline M. kansasii, M. chelonae & $5 \%$ & M. gordonae & $6 \%$ \\
\hline M. abscessus & $3 \%$ & M. abscessus & $5 \%$ \\
\hline M. xenopi & $2 \%$ & M. chelonae & $3 \%$ \\
\hline M. scrofulaceum & $1 \%$ & M. terrae complex, M. simiae complex & $2 \%$ \\
\hline $\begin{array}{l}\text { M. mucogenicum, M. szulgai, M. triplex, M. lentiflavum, } \\
\text { M. simiae complex, M. genavense }\end{array}$ & $<1 \%$ & $\begin{array}{l}\text { M. scrofulaceum, M. szulgai, M. peregrinum, M. xenopi, } \\
\text { M. flavescens, M. marinum }\end{array}$ & $<1 \%$ \\
\hline $\begin{array}{l}\text { M. malmoense, } \text { M. heckeshornense, } \\
\text { M. celatum, M. terrae complex }\end{array}$ & $\leq 0.1 \%$ & $\begin{array}{l}\text { M. shimodei, M. triviale, } \text { M. asiaticum, } \text { M. lentiflavum, M. malmoense, } \\
\text { M. nonchromogenicum, M. celatum, M. smegmatis, } \text {. parmense, } \\
\text { M. gilvum, M. mucogenicum, M. genavense, M. parascrofulaceum, } \\
\text { M. moriokaense, M. holsaticum, M. tuscicae, M. phlei, M. novocastrense, } \\
\text { M. porcinum, M. bohemicum, M. interjectum, M. neoaurum, M. alvei, } \\
\text { M. kubicae, M. sherrisii }\end{array}$ & $\leq 0.1 \%$ \\
\hline
\end{tabular}

the most prevalent species in a group of patients with symptoms of pulmonary disease $[35,40]$. A multi-country survey covering the period from 1991 to 1996 reported no M. kansasii isolates in Portugal, while in Brazil 12\% of the NTM analyzed belonged to this species [53]. The scenario in Portugal seems to have changed since then, as all Portuguese studies considered in the present review report the isolation of $M$. kansasii strains, although still with much lower frequency when compared with Brazil. Despite being a clinically relevant NTM species and a common cause of pulmonary infection, $M$. kansasii is often considered the most easily treatable NTM pathogen, as it is generally susceptible to common antituberculous drugs and shows a good correlation between in vitro susceptibility tests and clinical response [21,45]. However, the possibility of emergence of additional or increasingly resistant strains should not be discarded. As an example, although M. kansasii is reportedly sensitive to ethambutol [45], Telles and coworkers found a strikingly high ethambutol-resistance frequency in clinical relevant isolates from São Paulo [54].

\subsection{Pulmonary infections with Mycobacterium abscessus}

The isolation of Mycobacterium abscessus from respiratory samples is generally not as frequent as MAC and M. kansasii, but the threat posed by an M. abscessus pulmonary infection is often more serious and deserves particular attention. M. abscessus comprises two different subspecies, namely M. abscessus subsp. abscessus and M. abscessus subsp. bolletii, which has also recently included Mycobacterium massiliense [55]. Members of this species are remarkably resistant to chemotherapy and have been referred to as an "antibiotic nightmare" [56] for which there are no reliable antibiotic regimens recommended [45]. Genomic analyses revealed unique features and genetic resources that render them one of the most divergent species of the genus, which also helps explaining and translates into particular physiological trends [10]. In Rio de Janeiro, Mello and co-workers followed 174 patients with PNTM disease and among 12 NTM species involved, the lowest cure rate was observed among M. abscessus infection cases, basically related to the severe patterns of resistance of this strain [40]. Another study conducted in Piauí in 2007 with 9 patients with NTM disease, revealed that two were infected with $M$. abscessus. Both suffered treatment failures and one died 5 years after the diagnosis [43].

\subsection{Pulmonary infections with Mycobacterium fortuitum}

Mycobacterium fortuitum was initially isolated in Brazil in 1938 and the subsequent isolates were later classified as M. fortuitum subsp. fortuitum and M. fortuitum subsp. acetamidolyticum [57,58]. Commonly found in respiratory samples from Portugal and Brazil the isolation of $M$. fortuitum does not seem to be as clinically significant as the isolation of MAC, M. kansasii and M. abscessus. Often, it is merely indicative of transient colonization in patients with an underlying lung disease and does not progress even without antibiotic therapy directed at M. fortuitum [59]. However, it can cause pulmonary disease in humans, particularly in patients with gastroesophageal disorders [45]. Among the studies conducted in Portugal, there is at least one described case of lung disease caused by $M$. fortuitum meeting the ATS/IDSA criteria in a patient who had to receive specific antibiotic treatment based on in vitro susceptibility tests [28]. In São Paulo, Pedro and co-workers found 4 cases of confirmed M. fortuitum lung infection [34]. Another study conducted in Rio de Janeiro identified 11 cases meeting the ATS criteria, of which only 5 were successfully cured [40].

\subsection{Pulmonary infections with Mycobacterium gordonae}

Ubiquitous in the environment and in tap water, Mycobacterium gordonae is isolated very frequently from respiratory samples but rarely associated with disease, being regarded more as a contaminant than as a pathogen $[45,60]$. Isolates of this species have been identified in all Portuguese and in most Brazilian studies dealing with NTM respiratory isolates, reaching frequencies of over $30 \%$ of all NTM isolated in some cases [29,43]. It is more frequently isolated in Portugal than in Brazil (Table 2). When clinical relevance is assessed, though, most $M$. gordonae isolates are found not to be associated with disease. Nevertheless, M. gordonae pulmonary disease is not unheard-of even in immunocompetent individuals [60] and some cases in Portugal and Brazil have been reported. In Portugal, Campainha and co-workers identified 2 cases of pulmonary disease caused by M. gordonae [29]. In Brazil, 2 studies conducted in 2 different states reported 3 cases of $M$. gordonae lung disease each $[43,34]$. The 3 cases reported by Bona and co-workers were successfully treated with clarithromycin.

\subsection{Pulmonary infections with other less common NTM species}

In addition to the aforementioned NTM, 36 other species/complexes have been isolated from clinical samples in Portugal and Brazil, albeit less frequently (Table 2). Of these, only 15 are considered clinically relevant: Mycobacterium asiaticum, Mycobacterium celatum, Mycobacterium chelonae, Mycobacterium flavescens, Mycobacterium genavense, Mycobacterium lentiflavum, Mycobacterium malmoense, Mycobacterium moriokaense, Mycobacterium 
peregrinum, Mycobacterium scrofulaceum, Mycobacterium simiae complex, Mycobacterium smegmatis, Mycobacterium szulgai, Mycobacterium terrae complex and Mycobacterium xenopi (Table 1). Two other NTM species deserve special mention because they were recently discovered and first described in respiratory specimens from Brazilian patients with lung disease. In 2013, Ramos and coworkers described Mycobacterium fragae, closely related to M. celatum, from 3 clinical isolates of a Ceará patient with lung infection [61]. Even more recently, Fusco da Costa and co-workers described a new species within the $M$. simiae complex, which appears to be particularly prevalent in the state of Pará and was denominated Mycobacterium paraense [62].

\subsection{NTM pulmonary infection in cystic fibrosis patients}

NTM are increasingly recognized as clinically relevant infectious agents in cystic fibrosis (CF) patients, colonizing and infecting their lungs and capable of significantly affecting morbidity and mortality $[49,63,64]$. Worldwide, NTM isolation in respiratory samples has been reported in $6-22 \%$ of patients with $\mathrm{CF}$, with MAC and M. abscessus together accounting for over $90 \%$ of the cases [63]. It should be noted that in many cases a transient or persistent NTM colonization in CF patients does not progress to active pulmonary disease [64]. In Brazil, at least two studies have investigated this problem, one conducted in adults and the other in children. Paschoal and co-workers studied a population of adult CF patients with a less severe phenotype of the disease and found a colonization by NTM in $11 \%$ of the patients [65]. However, none of the patients were diagnosed with NTM disease and specific drug therapy was not prescribed. More recently, Cândido and co-workers reported a NTM frequency of $8 \%$ in CF children and performed species identification and antibiotic susceptibility tests with the isolated mycobacteria [66]. M. abscessus group species predominated followed by MAC and M. fortuitum. The antibiotic susceptibility profiles resulting from this study are alarming, with over $97 \%$ of the isolates being resistant to 5 or more drugs specifically used for mycobacterial infections, and one of the patients from whom one of these multidrug-resistant strains was isolated eventually developed PNTM disease without resolution to the date the article was elaborated [66].

\section{HIV infection and NTM disseminated disease}

The tight link between HIV infection and TB is widely known [67], but NTM also pose a serious threat and are a common cause of disease in AIDS patients [68]. NTM infection in AIDS patients may be present in the form of pulmonary disease, and it should be noted that many of the studies cited in section 2 include mixed samples of HIV-positive and HIV-negative persons. However, interpretation of NTM isolation from respiratory samples of HIV-positive patients requires additional considerations. Firstly, some species that are generally considered nonpathogenic and whose isolation from immunocompetent hosts is usually not clinically relevant have been associated with disease in HIVinfected persons [45]. Secondly, in the absence of evidence of pulmonary disease, isolation of NTM from respiratory samples of AIDS patients may indicate or foretell a case of NTM disseminated disease [45].

Diagnosis of NTM disseminated disease is usually performed through culture of clinical samples from sites presumed to be sterile of the patient, such as blood, bone marrow or lymph nodes [45]. In Portugal, the only data of NTM isolation from presumably sterile sites was reported by Couto and co-workers, who identified 14 MAC and one M. simiae isolates from blood cultures of patients with symptoms of mycobacteriosis [26], although the HIV-status of the patients was not reported. MAC (specifically ' $M$. avium subsp. hominissuis' in the vast majority of cases) is indeed the most frequently reported NTM associated with disseminated disease in HIV-positive patients, and the results from Brazilian studies are also consistent with this observation [69-71]. Other species isolated from presumed sterile sites of AIDS patients in these studies, and which were confirmedly involved in disseminated disease, were $M$. kansasii and $M$. scrofulaceum. M. lentiflavum has also been isolated from blood of a patient with NTM disseminated disease in Brazil who was also co-infected with $M$. avium [72], and a fatal case of $M$. simiae disseminated disease has also been described [73].

\section{Post-surgical infections with rapidly-growing mycobacteria}

Infection by RGM following invasive procedures has been described worldwide and increasingly in Brazil [74-76] leading to its recognition as a serious health problem by the Brazilian National Agency for Sanitary Surveillance (Agência Nacional de Vigilância Sanitária - ANVISA) [76]. Inadequate decontamination of surgical equipment, emergence and dissemination of disinfectant-resistant strains and their presence in antimicrobial solutions as well as lack of appropriate infection-control measures are very often the source of severe post-surgical infection outbreaks [77]. Several studies have focused on this issue in Brazil and detailed descriptions of RGM surgical-site infection outbreaks can be found in the literature. Environmental investigation following major outbreaks is increasingly performed to identify the source of infection and inform the adoption of preventive measures, although in a few cases only after the clinics have adopted the adequate measures and changed practices to contain the outbreaks, including thorough cleaning and disinfection of the more obvious potential sources of contamination, resulting in the source of infection never being conclusively identified $[78,79]$.

Unlike PNTM disease, NTM post-surgical infection cases are of compulsory notification in Brazil since 2009 due to the occurrence of outbreaks of unprecedented magnitude across the country, which led Brazilian health authorities to recognize these infections as a national health emergency [80]. In this section, the invasive health or cosmetic procedures most often associated with RGM post-surgical infections and outbreaks in Brazil over the last years are reviewed.

\subsection{Infectious keratitis with NTM}

Infectious mycobacterial keratitis is a rare complication of laserassisted in situ keratomileusis (LASIK), a commonly used vision correction surgical procedure that enhances the refractive condition of the cornea [81]. Several cases and outbreaks of post-LASIK mycobacterial infection have been described in Brazil, mainly involving $M$. chelonae. In fact, the first detailed descriptions of RGM surgical infections in Brazil were associated with this procedure [82]. M. chelonae was responsible for the 2 largest reported outbreaks. The first occurred in 1999 at a private clinic in Rio de Janeiro, with 65 eyes diagnosed with infectious keratitis following LASIK, of which 16 were confirmed to be positive for $M$. chelonae [83]. One year later another M. chelonae-caused keratitis outbreak emerged at a private clinic in São Paulo, affecting 10 patients treated by the same surgeon. A possible source of infection was identified during the investigation that followed, with evidence pointing to the portable steamer used to clean the microkeratome, whose water was found to be contaminated with $M$. chelonae [84]. In 1998, two patients who underwent LASIK at a private clinic in Rio 
de Janeiro developed surgical infections by M. abscessus. This mycobacteria was also responsible for 2 other cases at a clinic in São Paulo in 1999 and 2000 [83]. Although fluoroquinolones are often the antibiotics of choice for corneal infections, a subsequent investigation found that $M$. abscessus and $M$. chelonae isolates from these Brazilian outbreaks were highly resistant to this class of antibiotics, emphasizing the importance of early diagnosis of NTMcaused infections to expand therapeutic options [85]. Mycobacterium immunogenum was also implicated in an outbreak of keratitis in São Paulo involving 5 patients who underwent LASIK in 2003 [78].

\subsection{NTM infection in prosthetic valve endocarditis}

Prosthetic valve endocarditis (PVE) caused by NTM is a rare but documented complication of valve implant surgeries [86]. In São Paulo, a cluster of 13 implanted patients who developed PVE caused by $M$. chelonae has recently been reported [87]. All patients had received porcine valve implants between 1997 and 2002 and all the valves were from the same manufacturer. Investigation of 6 nonimplanted and supposedly sterile valves revealed contamination with $M$. chelonae, which led the hospital to discontinue their use. These cases were not the first of $M$. chelonae PVE described in Brazil [88] and persistence of viable $M$. chelonae in porcine valves after chemical treatment for use as biological prosthetic valves had already been investigated and discussed in the Brazilian literature [89].

\subsection{Post-mammoplasty NTM infections and the Campinas' outbreak}

Between 2002 and 2004, an outbreak of post-mammoplasty surgical-site infections emerged in the city of Campinas, state of São Paulo, affecting 35 patients. All but one of the 12 isolates recovered were identified as $M$. fortuitum. During this period, 5 patients who underwent mammoplasty surgery in other cities and one patient who had abdominal wall plastic surgery in Campinas were also diagnosed with $M$. fortuitum surgical-site infections, although molecular typing results suggested that this was a polyclonal outbreak with no signs of clone dissemination between hospitals [90]. The source of infection was never conclusively identified, but the investigation that followed raised suspicions regarding the use of reusable sizers, commonly employed by surgeons to estimate the volume of the definitive implant prior to its application [91]. This led ANVISA to temporarily suspend the use of the device [92] until the manufacturers introduced the necessary improvements, one of the measures that likely contributed to the elimination of post-mammoplasty NTM infections in the affected hospitals the year following the outbreak [91]. In fact, $M$. fortuitum is the NTM most frequently associated with post-mammoplasty infections in Brazil, responsible for more than half of the cases reported to the health surveillance system until 2009, followed by M. abscessus [93]. Other NTM infectious agents have been implicated namely Mycobacterium porcinum which was responsible for one of the Campinas' outbreak cases [90]. In 2010 the first case of Mycobacterium wolinskyi breast infection in Brazil was reported [94]. Cases involving M. peregrinum and M. smegmatis have also been reported [93]. The most recent ANVISA report on RGM infections shows that postmammoplasty mycobacterial infections are still an important health problem in Brazil despite the preventive measures enforced by ANVISA in the aftermath of the Campina's outbreak, with 85 cases reported between 2010 and 2014, including an outbreak in a Bahia clinic in 2013 [76].

\subsection{Epidemic of Mycobacterium massiliense surgical-site infections in Brazil}

Between 2004 and 2008, several Brazilian states faced nosocomial outbreaks involving a particular strain of Mycobacterium massiliense (recently reclassified as $M$. abscessus subsp. bolletii), often referred to as the BRA100 clone [55,95-97]. This nationwide epidemic began with the Belém outbreak in the state of Pará and involved 298 patients who had undergone laparoscopic surgeries in 16 different private hospitals in the city of Belém. A sample of 58 isolates were analyzed by $r p o B$ sequencing and PFGE molecular typing and identified as a single clone of M. massiliense [98]. As soon as the Belém outbreak started to subside in the middle of 2005 , an outbreak of surgical-site infections caused by the same strain of M. massiliense emerged in the state of Goiás, with 121 cases of patients diagnosed with NTM infection following laparoscopic and arthroscopic surgeries at 7 private hospitals in the city of Goiânia. Molecular typing and $r p o B$ sequencing of 18 sampled isolates revealed the unexpected link with the epidemic isolates from the distant city of Belém [99].

In the state of Rio de Janeiro, this same strain caused the largest outbreak of RGM postsurgical infections recorded to date in Brazil, with over 1000 patients possibly affected and 63 public and private hospitals involved [95]. Between August 2006 and July 2007, 1051 possible cases were reported in this state of which 172 were confirmed by laboratory techniques. All patients had undergone video-assisted surgery. Randomly selected isolates were analyzed by $r p o B$ and $h s p 65$ sequencing and PFGE fingerprinting, confirming their clonal identity with isolates from the Belém and Goiânia outbreaks [95]. Antimicrobial susceptibility tests revealed susceptibility to amikacin and clarithromycin and resistance to ciprofloxacin and doxycycline, as well as a high glutaraldehyde tolerance for BRA100 isolates $[95,100]$. This massive outbreak was followed by another in the state of Paraná, city of Curitiba, which lasted until January 2008 and involved 131 surgical patients from 7 private hospitals. Out of 39 isolates collected and analyzed, 36 were shown to belong to the M. massiliense BRA100 clone [96]. Other 3 outbreaks in the states of Espírito Santo, São Paulo, and Rio Grande do Sul were also found to be caused by this same strain [97].

All these outbreaks were associated with video-assisted surgeries involving the use of laparoscopic or arthroscopic equipment. At the time, all hospitals and clinics involved were using the same protocol for high-level disinfection of surgical equipment between surgeries: immersion in $2 \%$ glutaraldehyde for at least $30 \mathrm{~min}$. While this procedure is effective in eliminating reference strains of RGM, the BRA100 clone was found to be resistant to immersion in $2 \%$ glutaraldehyde for as much as $10 \mathrm{~h}$ [100]. This led the Brazilian health surveillance agency to immediately suspend this practice [80]. The glutaraldehyde-resistant phenotype in mycobacteria has been associated with defects in porin expression [101] and could in part account for the Brazilian $M$. massiliense epidemic. Further research in the BRA100 clone also showed increased virulence and in vivo pathogenicity of this strain when compared with a glutaraldehyde-sensitive $M$. massiliense reference strain [102]. In addition to this, inspections carried out by public health authorities revealed that some of the hospitals involved were breaching important protocols of infection control and prevention [99,103], which may also have played a role in the epidemic.

A study conducted in Rio Grande do Sul in the aftermath of the epidemic found that the BRA100 clone persisted in several hospitals of the state after the major 2004-2008 outbreaks, causing postsurgical infections and small outbreaks across the state at least until 2011 [104]. Perhaps the most worrying finding of this study was the resistance to clarithromycin shown by a significant 
proportion of the isolates involved in these more recent cases, something that had not yet been reported for the BRA100 clone.

Surprisingly, a recent study found remarkable genetic similarities between BRA100 epidemic isolates and M. massiliense isolates involved in an outbreak of respiratory infections in a cystic fibrosis center in the UK $[105,106]$, raising the intriguing and alarming possibility of intercontinental dissemination of a particularly disinfectant-resistant and virulent mycobacterial strain.

\subsection{Cutaneous NTM infections due to non-surgical invasive procedures}

In addition to post-surgical infections by RGM, infections associated with the use of invasive procedures for cosmetic or medical purposes have also been described in Brazil and Portugal. In Brazil, there have been several reports of mycobacterial infections and outbreaks associated with mesotherapy, a popular treatment to reduce localized fat performed in aesthetic clinics that consists of intradermal or subcutaneous topical injections of pharmacological substances. In 2000, the largest described outbreak involving NTM infections and mesotherapy took place at a private clinic in São Paulo state, with 43 people diagnosed with cutaneous infections. The infectious agent was identified as M. chelonae [83]. In 2002 there was another outbreak in a cosmetic clinic in the same state, with 7 confirmed cases of $M$. abscessus skin infection. In both cases, multiple mesotherapy sessions were reportedly performed with solutions stored in multiuse vials, a factor that may have contributed to the outbreaks [83]. Concomitantly with the Belém M. massiliense outbreak mentioned in section 4.4, a smaller outbreak caused by another $M$. abscessus subsp. bolletii strain affected 14 patients who underwent mesotherapy at a private clinic also in Belém [98]. M. fortuitum has also been associated with mesotherapy-acquired skin infections in São Paulo and Bahia $[107,108]$. Recently disclosed data reveals that over the last 4 years (2010-2014) mesotherapy-associated RGM infections have remained a concerning public health problem. Over this period, 63 cases were reported in Brazil, all involving illegal subcutaneous injections of phosphatidylcholine in the form of Lipostabil ${ }^{\circledR}$ for cosmetic purposes [76]. Worldwide, mesotherapy-associated NTM infections have been traced to contaminated injectable solutions or skin antiseptics and to inappropriate cleaning of injection devices with nonsterile tap water, but no environmental source was identified in these Brazilian outbreaks [109,110].

Acupuncture is also a procedure for which association with mycobacterial infections has been described worldwide. In Brazil, Castro-Silva and co-workers described one case of an immunosuppressed kidney transplant patient who developed a cutaneous Mycobacterium haemophilum infection after being prescribed with acupuncture for pain relief [111]. Skin lesion sites matched needle insertion sites perfectly, strongly suggesting inoculation during the acupuncture sessions. The patient reported lack of infection control measures by the acupuncture practitioner, namely that his skin was not cleaned prior to needle insertion and that the same reusable needles were used multiple times during the session. In Portugal, a case of $M$. fortuitum skin infection following acupuncture has also been reported [112].

Although there are no reports of NTM infections associated with tattooing in Portugal and Brazil, many cases and outbreaks of tattoo-associated NTM skin infections have emerged over the last decade, with reports from the USA, France, Germany, Spain, Scotland, Switzerland, Australia, Israel, Serbia and Thailand [113-116]. In almost all cases the source of infection was traced to the tattoo ink or to tap water used for ink dilution, and the species involved were M. chelonae, M. abscessus, M. haemophilum, M. fortuitum and M. immunogenum [116].

\section{High-risk environmental isolation of NTM}

The ubiquity of NTM in the environment and the very limited evidence of human-to-human transmission seem to point to the surrounding environment as the most likely source of human NTM infection and colonization $[19,106]$. Tap water in particular seems to be an important reservoir of these environmental species of mycobacteria, which are highly resistant to chlorine disinfection and thrive in showerhead biofilms [11,12]. In Lisbon, the detection of $M$. gordonae, $M$. intracellulare, $M$. kansasii and $M$. chelonae in the municipal water distribution system has been reported [117]. Coincidently, these four species are also among the most frequently isolated NTM in respiratory samples of Lisbon residents $[25,26]$.

NTM isolation from hospital settings is also common and poses a particularly serious risk for hospitalized patients, who are frequently more vulnerable to these opportunistic pathogens. Recognizing this threat, Restrepo and co-workers investigated the presence of NTM in samples of tap water, antiseptic solutions and surgical gloves from a university hospital of Manaus and concluded that the hospital water distribution system was colonized by several species of NTM. M. celatum and M. gordonae were the most frequently isolated species, followed by $M$. intracellulare, M. lentiflavum and Mycobacterium mucogenicum [118]. In a similar study carried out at a São Paulo hemodialysis center, Sartori and coworkers isolated M. lentiflavum, M. gordonae, M. kansasii, Mycobacterium gastri and M. szulgai in its hydric system and suggested that NTM biofilms in the center's plumbing and inadequate water decontamination processes were likely the source of the contamination [119]. M. lentiflavum was particularly abundant and seemed to persist and thrive in the hemodialysis center water system. Also in São Paulo, Souza and co-workers isolated NTM from exposed surfaces in the clinical environment of 2 health institutions and found both potentially pathogenic and rarely pathogenic species, including M. avium, $M$. fortuitum, M. kansasii, M. malmoense, M. lentiflavum, M. simiae, M. mucogenicum, M. smegmatis, M. flavescens, M. gastri, M. genavense, Mycobacterium vaccae and, the most frequent, M. gordonae [120]. In Portugal the lack of this type of environmental investigation is even more conspicuous than in Brazil. In a preliminary assessment we have recently isolated several drug resistant NTM strains from surfaces of a Portuguese central hospital belonging to the species $M$. gordonae, M. mucogenicum and Mycobacterium obuense (our unpublished results). Alarmingly, susceptibility tests revealed multidrug-resistant phenotypes to multiple classes of antibiotics ( $>5$ antibiotics recommended by Clinical \& Laboratory Standards Institute (CLSI) standards in addition to the 5 antibiotics used for selective isolation of mycobacteria).

\section{Future directions}

The therapeutic challenges posed by opportunistic mycobacteria are a direct consequence of their unique physiology and ecology, and will not be met without intensifying efforts into understanding their traits and finding new strategies for prevention and treatment of NTM infections. Because tap water seems to be one of the main routes of human exposure to NTM, reducing everyday exposure to these pathogens is necessarily tied to reducing their numbers in household and hospital plumbing premises. Measures to achieve this have been proposed based on recent research, including raising water heater temperature to $55^{\circ} \mathrm{C}$ and improving aeration [6]. Treating most NTM infections is currently an arduous task, limited by their intrinsic resistance to many known antibiotics. New drugs are urgently needed, and while attempts to test antibiotics developed for M. tuberculosis against NTM have produced disappointing results [121,122], the same avenues of research may be applied for the specific cases of NTM species. Some 
of these approaches include revealing and exploring novel targets against which new drugs can be designed through combining atomic-level analyses with protein chemistry and cell biology, repurposing and re-engineering existing compounds, and finding innovative immune-based strategies such as autophagy manipulation $[10,123,124]$.

\section{Concluding remarks}

The current status of NTM infections in Brazil is definitely alarming while in Portugal it is largely and worryingly unknown and severely underreported. In both countries, there is an urgent need for more and better-planned epidemiological surveys and for in-depth environmental investigations of NTM persistence in water and inanimate surfaces of high-risk sites, healthcare settings primarily. Even more critically, studies comparing environmental isolation of NTM with spatially and temporally related clinical cases of NTM infection are urgently required to better understand and manage the real risks of NTM exposure in different settings. The fact that the few existing studies already show the isolation of so many NTM strains from healthcare settings, some of which belonging to species often involved in serious human infections, is a matter of increasing concern and calls for the adoption of more effective and regular disinfection protocols. Our preliminary results obtained with a set of multidrug resistant strains recently isolated from a Portuguese tertiary hospital indicate that they are susceptible to common disinfectants, reinforcing the importance of implementing proper and regular disinfection procedures in NTM infection prevention. If cost reduction policies continue to hinder the implementation of adequate preventive measures in Portuguese hospitals and other healthcare institutions, the situation can rapidly run out of control and reach massive proportions, as was the case with the M. massiliense epidemic in Brazil.

In view of the therapeutic challenges posed by these opportunistic mycobacteria, it is also essential to get a clearer picture of antibiotic resistance profiles of NTM strains circulating in Portuguese and Brazilian hospitals. The unusually high and multiple resistances to antibiotics and disinfectants are hallmarks of the Mycobacterium genus, to which both intrinsic and acquired mechanisms contribute. Intrinsic drug resistance has been primarily attributed to mycobacteria's lipid rich cell envelope which confers low permeability to antibiotics and other chemotherapeutics agents [125]. More recently, efflux mechanisms have also been recognized as an important factor in the natural resistance of mycobacteria as they play an important role in mediating the efflux of drugs such as tetracycline, fluoroquinolones and aminoglycosides, among others [126-128]. Acquired drug resistance is generally mediated by horizontal transfer of genetic elements through plasmids, transposons or integrons. In M. tuberculosis, which has been specifically studied in the context of drug resistance/susceptibility, this type of resistance is caused mainly by chromosomal spontaneous or induced mutations, favoring the selection of resistant strains during sub-optimal drug therapeutic regimens [129]. In some clinically relevant NTM species, such as M. abscessus and M. fortuitum, an inducible mechanism of macrolide resistance has been found to confer in vivo acquired resistance to this class of antibiotics in some strains without affecting in vitro MIC values, which further complicates the already difficult task of choosing appropriate therapeutic schemes [21]. With no reliable and clearly defined antibiotic regimens and with a constantly changing and increasingly complex scenario, NTM antibiotic resistance surveillance is therefore mandatory in order to comprehensively understand this emerging health threat and to guide increasingly difficult therapeutic decisions.

\section{Acknowledgements}

We acknowledge the support of FEDER through COMPETE and of National Funds through FCT - Fundação para a Ciência e a Tecnologia grants FCOMP-01-0124-FEDER-028359 [PTDC/BIA-MIC/2779/ 2012] and UID/NEU/04539/2013.

Funding: None.

Competing interests: None declared.

Ethical approval: Not required.

\section{References}

[1] Legendre DP, Muzny CA, Swiatlo E. Hansen's disease (Leprosy): current and future pharmacotherapy and treatment of disease-related immunologic reactions. Pharmacotherapy 2012;32:27-37. http://dx.doi.org/10.1002/ PHAR.1009.

[2] Galagan JE. Genomic insights into tuberculosis. Nat Rev Genet 2014;15: 307-20. http://dx.doi.org/10.1038/nrg3664.

[3] Tamura K, Stecher G, Peterson D, Filipski A, Kumar S. MEGA6: molecular evolutionary genetics analysis version 6.0. Mol Biol Evol 2013;30:2725-9. http://dx.doi.org/10.1093/molbev/mst197.

[4] Olsen GI, Matsuda H, Hagstrom R, Overbeek R. fastDNAmL: a tool for construction of phylogenetic trees of DNA sequences using maximum likelihood. Comput Appl Biosci 1994;10:41-8.

[5] Saitou N, Nei M. The neighbor-joining method: a new method for reconstructing phylogenetic trees'. Mol Biol Evol 1987;4:406-25.

[6] Falkinham JO. Environmental sources of nontuberculous mycobacteria. Clin Chest Med 2015;36:35-41. http://dx.doi.org/10.1016/j.ccm.2014.10.003.

[7] Tortoli E. Impact of genotypic studies on mycobacterial taxonomy: the new mycobacteria of the 1990s. Clin Microbiol Rev 2003;16:319-54. http:// dx.doi.org/10.1128/CMR.16.2.319-354.2003.

[8] Tortoli E. Microbiological features and clinical relevance of new species of the genus Mycobacterium. Clin Microbiol Rev 2014;27:727-52. http:// dx.doi.org/10.1128/CMR.00035-14

[9] Falkinham JO. Impact of human activities on the ecology of Nontuberculous mycobacteria. Future Microbiol 2010;5:951-60. http://dx.doi.org/10.2217/ fmb.10.53.

[10] Nobre A, Alarico S, Maranha A, Mendes V, Empadinhas N. The molecular biology of mycobacterial trehalose in the quest for advanced tuberculosis therapies. Microbiol (United Kingdom) 2014;160:1547-70. http:/ dx.doi.org/10.1099/mic.0.075895-0.

[11] Le Dantec C, Duguet J, Montiel A, Dumoutier N, Dubrou S, Vincent V. Chlorine disinfection of atypical mycobacteria isolated from a water distribution system. Appl Environ Microbiol 2002;68:1025-32. http://dx.doi.org/ 10.1128/AEM.68.3.1025.

[12] Feazel LM, Baumgartner LK, Peterson KL, Frank DN, Harris JK, Pace NR Opportunistic pathogens enriched in showerhead biofilms. Proc Natl Acad Sci U. S. A 2009;106:16393-9. http://dx.doi.org/10.1073/pnas.0908446106.

[13] Shinnick TM, Good RC. Mycobacterial taxonomy. Eur J Clin Microbiol Infect Dis 1994;13:884-901. http://dx.doi.org/10.1128/CMR.16.2.319-354.2003.

[14] De Groote MA, Huitt G. Infections due to rapidly growing mycobacteria. Clin Infect Dis 2006;42:1756-63. http://dx.doi.org/10.1086/504381.

[15] Bodle EE, Cunningham JA, Della-Latta P, Schluger NW, Saiman L. Epidemiology of nontuberculous mycobacteria in patients without HIV infection, New York City. Emerg Infect Dis 2008;14:390-6. http://dx.doi.org/10.3201/ eid1403.061143.

[16] Kendall B, Winthrop K. Update on the epidemiology of pulmonary nontuberculous mycobacterial infections. Semin Respir Crit Care Med 2013;34: 87-94. http://dx.doi.org/10.1055/s-0033-1333567.

[17] Wentworth $A B$, Drage LA, Wengenack NL, Wilson JW, Lohse CM. Increase incidence of cutaneous nontuberculous mycobacterial infection, 1980 to 2009: a population-based study. Mayo Clin Proc 2013;88:38-45. http:// dx.doi.org/10.1016/j.mayocp.2012.06.029.

[18] Panagiotou M, Papaioannou AI, Kostikas K, Paraskeua M, Velentza E Kanellopoulou $\mathrm{M}$, et al. The epidemiology of pulmonary nontuberculous mycobacteria: data from a general hospital in Athens, Greece, 2007-2013. Pulm Med 2014;2014:9. http://dx.doi.org/10.1155/2014/894976.

[19] Falkinham JO. Surrounded by mycobacteria: nontuberculous mycobacteria in the human environment. J Appl Microbiol 2009;107:356-67. http:// dx.doi.org/10.1111/j.1365-2672.2009.04161.x.

[20] World Health Organization. Tuberculosis country profiles. 2014. www.who. int/tb/data [accessed 25.08.15].

[21] Griffith DE. Nontuberculous mycobacterial lung disease. Curr Opin Infect Dis 2010;23:185-90. http://dx.doi.org/10.1097/OCO.0b013e328336ead6.

[22] McShane PJ, Glassroth J. Pulmonary disease due to nontuberculous mycobacteria: current state and new insights. Chest 2015;307:980251. http:// dx.doi.org/10.1378/chest.15-0458. 
[23] Arend SM, van Soolingen D, Ottenhoff THM. Diagnosis and treatment of lung infection with nontuberculous mycobacteria. Curr Opin Pulm Med 2009;15: 201-8. http://dx.doi.org/10.1097/MCP.0b013e3283292679.

[24] Prevots DR, Marras TK. Epidemiology of human pulmonary infection with nontuberculous mycobacteria. Clin Chest Med 2015;36:13-34. http:// dx.doi.org/10.1016/j.ccm.2014.10.002.

[25] Amorim A, Macedo R, Lopes A, Rodrigues I, Pereira E. Non-tuberculous mycobacteria in HIV-negative patients with pulmonary disease in Lisbon, Portugal. Scand J Infect Dis 2010;42:626-8. http://dx.doi.org/10.3109/ 00365541003754485.

[26] Couto I, Machado D, Viveiros M, Rodrigues L, Amaral L. Identification of nontuberculous mycobacteria in clinical samples using molecular methods: a 3-year study. Clin Microbiol Infect 2010;16:1161-4. http://dx.doi.org/ 10.1111/j.1469-0691.2009.03076.x.

[27] Dabó H, Santos V, Marinho A, Ramos A, Carvalho T, Riberio M, et al. Nontuberculous mycobacteria - respiratory specimens isolation and its clinical significance. Eur Respir J 2014;44:P2509.

[28] Van Zeller M, Campainha S, Duarte R. Nontuberculous mycobacteria presentation, diagnosis and response to treatment [in Portuguese] Rev Port Pneumol 2013;19:49-50. http://dx.doi.org/10.1016/j.rppneu.2012. 04.005.

[29] Campainha S, Braga R, Valente I, Carvalho A, Duarte R. Nontuberculous mycobacteria - isolation in respiratory specimens and its clinical relevance. Eur Respir J 2011;38:3393.

[30] Marinho A, Fernandes G, Carvalho T, Pinheiro D, Gomes I. Nontuberculous mycobacteria in non-AIDS patients. Rev Port Pneumol 2008;XIV:323-37.

[31] Barreto A, Campos C. Nontuberculous mycobacteria in Brazil [in Portuguese] Bol Pneumol Sanitária 2000;8:23-32.

[32] Bensi EPA, Panunto PC, Ramos MC. Incidence of tuberculous and nontuberculous mycobacteria, differentiated by multiplex PCR, in clinical specimens of a large general hospital. Clinics 2013;68:179-83. http://dx.doi.org/ 10.6061/clinics/2013(02)OA10.

[33] Zamarioli LA, Gobetti A, Pereira CM, Ferrazoli L, Bammann R. Laboratory identification of mycobacteria in respiratory samples from HIV-positive patients suspected of tuberculosis [in Portuguese] Rev Soc Bras Med Trop 2009;42:290-7. http://dx.doi.org/10.1590/S0037-86822009000300010.

[34] Pedro HDSP, Pereira MIF, Goloni MDRA, Ueki SYM, Chimara E. Nontuberculous mycobacteria isolated in São José do Rio Preto, Brazil between 1996 and 2005. J Bras Pneumol 2008;34:950-5. http://dx.doi.org/10.3109/ 14653249.2011 .613927$.

[35] Zamarioli LA, Coelho A, Pereira CM, Nascimento AC, Ueki SYM, Chimara E. Descriptive study of the frequency of nontuberculous mycobacteria in the Baixada Santista of the state of São Paulo, Brazil. J Bras Pneumol 2008;34: 590-4. http://dx.doi.org/10.1590/S1806-37132008000800008.

[36] Ueki SYM, Martins MC, Telles MA da S, Virgilio MC, Giampaglia CMS, Chimara E, et al. Nontuberculous mycobacteria: species diversity in São Paulo state, Brazil [in Portuguese] J Bras Patol Med Lab 2005;41:1-8. http:/ dx.doi.org/10.1590/S1676-24442005000100003.

[37] Chimara E, Giampaglia CMS, Martins MC, Telles MADS, Ueki SYM, Ferrazoli L. Molecular characterization of Mycobacterium kansasii isolates in the state of São Paulo between 1995-1998. Mem Inst Oswaldo Cruz 2004;99:739-43. http://dx.doi.org/10.1590/S0074-02762004000700013.

[38] Fusco da Costa AR, Falkinham JO, Lopes ML, Barretto AR, Felicio JS, Sales LHM, et al. Occurrence of nontuberculous mycobacterial pulmonary infection in an endemic area of tuberculosis. PLoS Negl Trop Dis 2013;7:e2340. http:// dx.doi.org/10.1371/journal.pntd.0002340.

[39] Fusco da Costa AR, Lopes ML, Sousa MS De, Suffys PN, Helena L, Sales M, et al Pulmonary nontuberculous mycobacterial infections in the state of para, an endemic region for tuberculosis in North of Brazil. In: Amal A, editor. Pulm Infect, InTech; 2012. http://dx.doi.org/10.5772/28559.

[40] KGC de Mello, Mello FCQ, Borga L, Rolla V, Duarte RS, Sampaio EP, et al. Clinical and therapeutic features of pulmonary nontuberculous mycobacterial disease, Brazil, 1993-2011. Emerg Infect Dis 2013;19:393-9. http:/ dx.doi.org/10.3201/eid/1903.120735.

[41] Lima CAM, Gomes HM, Oelemann MAC, Ramos JP, Caldas PC, Campos CED, et al. Nontuberculous mycobacteria in respiratory samples from patients with pulmonary tuberculosis in the state of Rondônia, Brazil. Mem Ins Oswaldo Cruz 2013;108:457-62. http://dx.doi.org/10.1590/0074-027610 8042013010.

[42] Agertt VA, Dalmolin TV, Bonez PC, Mizdal CR, Marques JB, Flores V da C, et al. Identification of mycobacteria isolated at university hospital of Santa Maria Rio Grande do sul, Brazil. J Bras Patol Med Lab 2013;49:115-7. http:/| dx.doi.org/10.1590/s1676-24442013000200006.

[43] Bona MGM, Leal MJS, Martins LMS, Silva RN, Castro JAF, Monte SJH. Restriction enzyme analysis of the hsp65 gene in clinical isolates from patients suspected of having pulmonary tuberculosis in Teresina, Brazil. J Bras Pneumol 2011;37:628-35. http://dx.doi.org/10.1590/S1806-37132011000 500010.

[44] Matos ED, Santana MA, de Santana MC, Mamede P, Bezerra BL, Panão ED, et al. Nontuberculosis mycobacteria at a multiresistant tuberculosis reference center in Bahia: clinical epidemiological aspects. Braz J Infect Dis 2004:8:296-304. S1413-86702004000400005.

[45] Griffith DE, Aksamit T, Brown-Elliott BA, Catanzaro A, Daley C, Gordin F, et al. An official ATS/IDSA statement: diagnosis, treatment, and prevention of nontuberculous mycobacterial diseases. Am J Respir Crit Care Med 2007;175: 367-416. http://dx.doi.org/10.1164/rccm.200604-571ST.

[46] Philley JV, Griffith DE. Treatment of slowly growing mycobacteria. Clin Chest Med 2015;36:79-90. http://dx.doi.org/10.1016/j.ccm.2014.10.005.

[47] Kasperbauer SH, De Groote MA. The treatment of rapidly growing mycobacterial infections. Clin Chest Med 2015;36:67-78. http://dx.doi.org/ 10.1016/j.ccm.2014.10.004.

[48] Fusco da Costa AR, Lopes ML, Leão SC, Schneider MPC, Sousa MS, Suffys PN, et al. Molecular identification of rapidly growing mycobacteria isolates from pulmonary specimens of patients in the state of Pará, Amazon region, Brazil. Diagn Microbiol Infect Dis 2009;65:358-64. http://dx.doi.org/10.1016/ j.diagmicrobio.2009.08.003.

[49] Adjemian J, Olivier KN, Prevots DR. Nontuberculous mycobacteria among patients with cystic fibrosis in the United States. Screening practices and environmental risk. Am J Respir Crit Care Med 2014;190:581-6. http:// dx.doi.org/10.1164/rccm.201405-08840C.

[50] Thorel MF, Krichevsky M, Lévy-Frébault VV. Numerical taxonomy of mycobactin-dependent mycobacteria, emended description of Mycobacterium avium, and description of Mycobacterium avium subsp. avium subsp. nov., Mycobacterium avium subsp. paratuberculosis subsp. nov., and Mycobacterium avium subsp. silvaticum subsp. nov. Int J Syst Bacteriol 1990;40:254-60. http://dx.doi.org/10.1099/00207713-40-3-254.

[51] Mijs W, de Haas P, Rossau R, Van Der Laan T, Rigouts L, Portaels F, et al. Molecular evidence to support a proposal to reserve the designation Mycobacterium avium subsp. avium for bird-type isolates and " $M$. avium subsp. hominissuis" for the human/porcine type of M. avium. Int J Syst Evol Microbiol 2002:52:1505-18. http://dx.doi.org/10.1099/ijs.0.02037-0.

[52] Field SK, Fisher D, Cowie RL. Mycobacterium avium complex pulmonary disease in patients without HIV infection. Chest 2004;126:566-81. http:// dx.doi.org/10.1378/chest.126.2.566.

[53] Martín-Casabona N, Bahrmand AR, Bennedsen J, Østergaard Thomsen V, Curcio M, Fauville-Dufaux M, et al. Non-tuberculous mycobacteria: patterns of isolation. A multi-country retrospective survey. Int J Tuberc Lung Dis 2004;8:1186-93.

[54] Telles MA da S, Chimara E, Ferrazoli L, Riley LW. Mycobacterium kansasii: antibiotic susceptibility and PCR-restriction analysis of clinical isolates. J Med Microbiol 2005;54:975-9. http://dx.doi.org/10.1099/jmm.0.45965-0.

[55] Leao SC, Tortoli E, Paul Euzé J, Garcia MJ. Proposal that Mycobacterium massiliense and Mycobacterium bolletii be united and reclassified as Mycobacterium abscessus subsp. bolletii comb. nov., designation of Mycobacterium abscessus subsp. abscessus subsp. nov. and emended description of Mycobacterium abscessus. Int J Syst Evol Microbiol 2011;61:2311-3. http:// dx.doi.org/10.1099/ijs.0.023770-0.

[56] Nessar R, Cambau E, Reyrat JM, Murray A, Gicquel B. Mycobacterium abscessus: a new antibiotic nightmare. J Antimicrob Chemother 2012;67: 810-8. http://dx.doi.org/10.1093/jac/dkr578.

[57] Da Costa Cruz JC. Mycobacterium fortuitum um novo bacillo acidoresistance pathogenico para o homen. Acta Medica (Rio Jan 1938;1:297-301.

[58] Tsukamura M, Yano I, Imaeda T. Mycobacterium fortuitum subspecies acetamidolyticum, a new subspecies of Mycobacterium fortuitum. Microbiol Immunol 1986;30:97-110.

[59] Park S, Suh GY, Chung MP, Kim H, Kwon OJ, Lee KS, et al. Clinical significance of Mycobacterium fortuitum isolated from respiratory specimens. Respir Med 2008;102:437-42. http://dx.doi.org/10.1016/j.rmed.2007.10.005.

[60] Mazumder SA, Hicks A, Norwood J. Mycobacterium gordonae pulmonary infection in an immunocompetent adult. N Am J Med Sci 2010;2:205-7.

[61] Ramos JP, Campos CED, Caldas PCDS, Ferreira NV, da Silva MVB, Redner P, et al. Mycobacterium fragae sp. nov., a non-chromogenic species isolated from human respiratory specimens. Int J Syst Evol Microbiol 2013;63: 2583-7. http://dx.doi.org/10.1099/ijs.0.046862-0.

[62] Fusco da Costa AR, Fedrizzi T, Lopes ML, Pecorari M, Oliveira da Costa WL, Giacobazzi E, et al. Characterization of 17 strains belonging to the Mycobacterium simiae complex and description of Mycobacterium paraense sp. nov. Int J Syst Evol Microbiol 2015;65:656-62. http://dx.doi.org/10.1099/ ijs.0.068395-0.

[63] Qvist T, Pressler T, Høiby N, Katzenstein TL. Shifting paradigms of nontuberculous mycobacteria in cystic fibrosis. Respir Res 2014;15:41. http:// dx.doi.org/10.1186/1465-9921-15-41.

[64] Martiniano SL, Nick JA. Nontuberculous mycobacterial infections in cystic fibrosis. Clin Chest Med 2015;36:101-15. http://dx.doi.org/10.1016/ j.ccm.2014.11.003.

[65] Paschoal IA, De Oliveira Villalba W, Bertuzzo CS, Cerqueira EMFP, Pereira MC. Cystic fibrosis in adults. Lung 2007;185:81-7. http://dx.doi.org/10.1007/ s00408-006-2597-0.

[66] Cândido PHC, Nunes LDS, Marques EA, Folescu TW, Coelho FS, de Moura VCN, et al. Multidrug-resistant nontuberculous mycobacteria isolated from cystic fibrosis patients. J Clin Microbiol 2014;52:2990-7. http://dx.doi.org/ 10.1128/JCM.00549-14.

[67] Pawlowski A, Jansson M, Sköld M, Rottenberg ME, Källenius G. Tuberculosis and HIV co-infection. PLoS Pathog 2012;8:e1002464. http://dx.doi.org/ 10.1371/journal.ppat.1002464.

[68] Alvarez-Uria G, Falcó V, Martín-Casabona N, Crespo M, Villar Del Saz S, Curran A, et al. Non-tuberculous mycobacteria in the sputum of HIV-infected patients: infection or colonization? Int J STD AIDS 2009;20:193-5. http:// dx.doi.org/10.1258/ijsa.2008.008300. 
[69] Ferreira RMC, Saad MHF, Da Silva MG, De Souza Fonseca L. Non-tuberculous mycobacteria I: one year clinical isolates identification in tertiary hospital aids reference center, Rio de Janeiro, Brazil, in pre highly active antiretroviral therapy era. Mem Inst Oswaldo Cruz 2002;97:725-9. http://dx.doi.org/ 10.1590/S0074-02762002000500024.

[70] Senna SG, Marsico AG, Betzler G, Vieira DO, Sobral LF, Suffys PN, et al. Identification of nontuberculous mycobacteria isolated from clinical sterile sites in patients at a university hospital in the city of Rio de Janeiro, Brazil. J Bras Pneumol 2011;37:521-6. http://dx.doi.org/10.1590/S1806-371320 11000400015.

[71] Oplustil CP, Leite OH, Oliveira MS, Sinto SI, Uip DE, Boulos M, et al. Detection of mycobacteria in the bloodstream of patients with acquired immunodeficiency syndrome in a university hospital in Brazil. Braz J Infect Dis 2001;5:252-9. http://dx.doi.org/10.1590/S1413-8670200100 0500003.

[72] Suffys P, Da Silva Rocha A, Brandão A, Vanderborght B, Mijs W, Jannes G, et al. Detection of mixed infections with Mycobacterium lentiflavum and Mycobacterium avium by molecular genotyping methods. J Med Microbiol 2006;55:127-31. http://dx.doi.org/10.1099/jmm.0.46218-0.

[73] Sampaio JL, Artiles N, Pereira RM, Souza JR, Leite JP. Mycobacterium simiae infection in a patient with acquired immunodeficiency syndrome. Braz J Infect Dis 2001;5:352-5. http://dx.doi.org/10.1590/S1413-86702001000 600010.

[74] Cabral DB, Andrade D. Nontuberculous mycobacteria in surgery: challenges likely to be faced in Brazil? Acta Paul Enferm 2011;24:715-20. http:// dx.doi.org/10.1590/S0103-21002011000500020.

[75] Pitombo MB, Lupi O, Duarte RS. Infections by rapidly growing mycobacteria resistant to disinfectants: a national matter? [in Portuguese] Rev Bras Ginecol E Obs 2009;31:529-33. http://dx.doi.org/10.1590/S0100-72032 009001100001.

[76] ANVISA. Infecções por Micobactérias de Crescimento Rápido (MCR) relacionadas a procedimentos invasivos em serviços de saúde e clínicas cosméticas, no período de Janeiro de 2010 a setembro de 2014 [in Portuguese]. 2014.

[77] Wildner LM, Nogueira CL, Souza S, Senna SG, Silva R, Bazzo ML. Mycobacteria: epidemiology and diagnostic [in Portuguese] Rev Patol Trop 2011;40: 207-29.

[78] Sampaio JLM, Junior DN, Freitas D, Höfling-Lima AL, Miyashiro K, Alberto FL, et al. An outbreak of keratitis caused by Mycobacterium immunogenum. J Clin Microbiol 2006;44:3201-7. http://dx.doi.org/10.1128/JCM.00656-06.

[79] Song JY, Sohn JW, Jeong HW, Cheong HJ, Kim WJ, Kim MJ. An outbreak of post-acupuncture cutaneous infection due to Mycobacterium abscessus. BMC Infect Dis 2006;6. http://dx.doi.org/10.1186/1471-2334-6-6.

[80] ANVISA. RESOLUÇÃO - RDC No8 de 27 de Fevereiro de 2009 [in Portuguese]. 2009. p. $1-3$.

[81] Sharma DP, Sharma S, Wilkins MR. Microbial keratitis after corneal laser refractive surgery. Future Microbiol 2011;6:819-31. http://dx.doi.org/ 10.2217/fmb.11.61.

[82] Lorena NSDO, Pitombo MB, Côrtes PB, Maya MCA, Silva MG Da, Carvalho ACDS, et al. Mycobacterium massiliense BRA100 strain recovered from postsurgical infections: resistance to high concentrations of glutaraldehyde and alternative solutions for high level disinfection. Acta Cir Bras 2010;25:455-9. http://dx.doi.org/10.1590/S0102-86502010000500013.

[83] Sampaio JLM, Viana-Niero C, Freitas D, Höfling-Lima AL, Leão SC. Enterobacterial repetitive intergenic consensus PCR is a useful tool for typing Mycobacterium chelonae and Mycobacterium abscessus isolates. Diagn Microbiol Infect Dis 2006;55:107-18. http://dx.doi.org/10.1016/ j.diagmicrobio.2006.01.006.

[84] Freitas D, Alvarenga L, Sampaio J, Mannis M, Sato E, Sousa L, et al. An outbreak of Mycobacterium Chelonae infection after LASIK. Ophthalmology 2003;110:276-85. http://dx.doi.org/10.1016/S0161-6420(02) 01643-3.

[85] Hofling-Lima AL, Freitas D, Luiz J, Sampaio JLM, Leão SC, Contarini P. In vitro activity of fluoroquinolones against Mycobacterium abscessus and Mycobacterium chelonae. Cornea 2005:24:730-4.

[86] Bush LM, Paturi A, Chaparro-Rojas F, Perez MT. Mycobacterial prosthetic valve endocarditis. Curr Infect Dis Rep 2010;12:257-65. http://dx.doi.org/ 10.1007/s11908-010-0108-1.

[87] Strabelli TMV, Siciliano RF, Castelli JB, Demarchi LMMF, Leão SC, VianaNiero C, et al. Mycobacterium chelonae valve endocarditis resulting from contaminated biological prostheses. J Infect 2010;60:467-73. http:// dx.doi.org/10.1016/j.jinf.2010.03.008.

[88] Jorge S, Gondim F, Arnoni A, Zamorano M, Garcia D, Sousa J. Endocarditis in valvular prosthesis caused by Mycobacterium chelonei [in Portuguese] Arq Bras Cardiol 1994;63:121-5.

[89] Casagrande ISJ, Lucciola J, Salles CA, Horizonte B. Atypical mycobacteria in bioprosthesis: potential cause of endocarditis with negative cultures [in Portuguese] Rev Bras Cir Cardiovasc 1986;1:40-3.

[90] Sampaio JLM, Chimara E, Ferrazoli L, da Silva Telles MA, Del Guercio VMF, Jericó ZVN, et al. Application of four molecular typing methods for analysis of Mycobacterium fortuitum group strains causing post-mammaplasty infections. Clin Microbiol Infect 2006;12:142-9. http://dx.doi.org/10.1111/ j.1469-0691.2005.01312.x.

[91] Padoveze MC, Fortaleza CMCB, Freire MP, Brandão de Assis D, Madalosso G, Pellini ACG, et al. Outbreak of surgical infection caused by non-tuberculous mycobacteria in breast implants in Brazil. J Hosp Infect 2007;67:161-7. http://dx.doi.org/10.1016/j.jhin.2007.07.007.

[92] ANVISA. RESOLUÇÃO - RE N ${ }^{\circ} 689$ de 28 de Abril de 2004 [in Portuguese] 2004. p. 1.

[93] ANVISA. Relatório descrito de investigação de casos de infecções por Micobactérias Não tuberculosas de Crescimento Rápido (MCR) no Brasil no período de 1998 a 2009 [in Portuguese]. 2011.

[94] Lima AS, Neves MMC, Gomes KM, Guarines KM, Luna CF, Duarte RS, et al First case report of infection by Mycobacterium wolinskyi after mammoplasty in Brazil. Infect Dis Rep 2013;5:e12. http://dx.doi.org/10.4081/ idr.2013.e12.

[95] Duarte RS, Lourenço MCS, Fonseca LDS, Leão SC, Amorim EDLT, Rocha ILL et al. Epidemic of postsurgical infections caused by Mycobacterium massiliense. J Clin Microbiol 2009;47:2149-55. http://dx.doi.org/10.1128/ JCM.00027-09.

[96] Monego F, Duarte RS, Nakatani SM, Araújo WN, Riediger IN, Brockelt S, et al Molecular identification and typing of Mycobacterium massiliense isolated from postsurgical infections in Brazil. Braz J Infect Dis 2011;15:436-41. http://dx.doi.org/10.1016/S1413-8670(11)70224-0.

[97] Leão SC, Viana-Niero C, Matsumoto CK, Valeria K, Lima B, Lopes ML, et al. Epidemic of surgical-site infections by a single clone of rapidly growing mycobacteria in Brazil. Future Microbiol 2010;5:971-80. http://dx.doi.org/ 10.2217/fmb.10.49.

[98] Viana-Niero C, Lima KVB, Lopes ML, Rabello MCDS, Marsola LR, Brilhante VCR, et al. Molecular characterization of Mycobacterium massiliense and Mycobacterium bolletii in isolates collected from outbreaks of infections after laparoscopic surgeries and cosmetic procedures. J Clin Microbiol 2008;46:850-5. http://dx.doi.org/10.1128/JCM.02052-07.

[99] Cardoso AM, Martins de Sousa E, Viana-Niero C, Bonfim de Bortoli F, Pereira das Neves ZC, Leão SC, et al. Emergence of nosocomial Mycobacterium massiliense infection in Goiás. Braz Microbes Infect 2008;10:1552-7. http:// dx.doi.org/10.1016/j.micinf.2008.09.008.

[100] Lorena N, Duarte R, Pitombo M. Rapidly growing mycobacteria infection after videosurgical procedures - The glutaraldehyde hypothesis [in Portuguese] Rev Col Bras Cir 2009;36:266-7. http://dx.doi.org/10.1590/S010069912009000300015.

[101] Svetlíková Z, Škovierová H, Niederweis M, Gaillard JL, McDonnell G Jackson M. Role of porins in the susceptibility of Mycobacterium smegmatis and Mycobacterium chelonae to aldehyde-based disinfectants and drugs. Antimicrob Agents Chemother 2009;53:4015-8. http://dx.doi.org/10.1128/ AAC.00590-09.

[102] Shang S, Gibbs S, Henao-Tamayo M, Shanley CA, McDonnell G, Duarte RS et al. Increased virulence of an epidemic strain of mycobacterium massiliense in mice. PLoS One 2011;6. http://dx.doi.org/10.1371/ journal.pone.0024726.

[103] Macedo JLS, Maierovitch C, Henriques P. Postoperative infections due to rapidly growing mycobacteria in Brazil [in Portuguese] Rev Bras Cir Plást 2009:24:544-51.

[104] Nunes LDS, Baethgen LF, Ribeiro MO, Cardoso CM, de Paris F, De David SMM, et al. Outbreaks due to Mycobacterium abscessus subsp. bolletii in southern Brazil: persistence of a single clone from 2007 to 2011. J Med Microbiol 2014;63:1288-93. http://dx.doi.org/10.1099/jmm.0.074906-0.

[105] Davidson RM, Hasan NA, de Moura VCN, Duarte RS, Jackson M, Strong M. Phylogenomics of Brazilian epidemic isolates of Mycobacterium abscessus subsp. bolletii reveals relationships of global outbreak strains. Infect Genet Evol 2013;20:292-7. http://dx.doi.org/10.1016/ j.meegid.2013.09.012.

[106] Bryant JM, Grogono DM, Greaves D, Foweraker J, Roddick I, Inns T, et al. Whole-genome sequencing to identify transmission of Mycobacterium abscessus between patients with cystic fibrosis: a retrospective cohort study. Lancet 2013;381:1551-60. http://dx.doi.org/10.1016/S0140-6736(13 60632-7.

[107] Sousa AC, Pereira C, Guimarães N, Rego V, Paixão A, Barbosa AJ. Atypical cutaneous mycobacteriosis following mesotherapy. An Bras Dermatol 2001;76:711-5.

[108] Herreros FOC, Velho PENF, De Moraes AM, Cintra ML. Cutaneous atypical mycobacteriosis after ultrasound hydrolipoclasia treatment. Dermatol Surg 2009;35:158-60. http://dx.doi.org/10.1111/j.1524-4725.2008.34401.x.

[109] Carbonne A, Brossier F, Arnaud I, Bougmiza I, Caumes E, Meningaud JP, et al. Outbreak of nontuberculous mycobacterial subcutaneous infections related to multiple mesotherapy injections. J Clin Microbiol 2009;47:1961-4. http:// dx.doi.org/10.1128/JCM.00196-09.

[110] Del Castillo M, Palmero D, Lopez B, Paul R, Ritacco V, Bonvehi P, et al. Mesotherapy-associated outbreak caused by Mycobacterium immunogenum. Emerg Infect Dis 2009;15:357-9. http://dx.doi.org/10.1136/ adc.87.3.202.

[111] Castro-Silva AN, Freire AO, Grinbaum RS, Elmor de Araújo MR, Abensur H, Araújo MRT, et al. Cutaneous Mycobacterium haemophilum infection in a kidney transplant recipient after acupuncture treatment. Transpl Infect Dis 2011;13:33-7. http://dx.doi.org/10.1111/j.1399-3062.2010.00522.x.

[112] Cordeiro M, Mascarenhas R, Reis J, Tellechea O, Figueiredo A. Mycobacteria infection after acupuncture. J Eur Acad Dermatol Venereol 2003;17:186.

[113] Kennedy BS, Bedard B, Younge M, Tuttle D, Ammerman E, Ricci J, et al. Infection associated with tattoo ink. N Engl J Med 2012;367:1020-4. http:// dx.doi.org/10.1056/NEJMoa1205114. 
[114] Kluger N, Muller C, Gral N. Atypical mycobacteria infection following tattooing: review of an outbreak in 8 patients in a French tattoo parlor. Arch Dermatol 2008;144:941-2. http://dx.doi.org/10.1001/archderm.144.7.941.

[115] Hamsch C, Hartschuh W, Enk A, Flux K. A chinese tattoo paint as a vector of atypical mycobacteria-outbreak in 7 patients in Germany. Acta Derm Venereol 2011;91:63-4. http://dx.doi.org/10.2340/00015555-1015.

[116] Conaglen PD, Laurenson IF, Sergeant A, Thorn SN, Rayner A, Stevenson J. Systematic review of tattoo-associated skin infection with rapidly growing mycobacteria and public health investigation of a cluster in Scotland Eurosurveillance 2010;2013(18):20553.

[117] Santos R, Oliveira F, Fernandes J, Gonçalves S, Macieira F, Cadete M. Detection and identification of mycobacteria in the Lisbon water distribution system. Water Sci Technol 2005;52:177-80.

[118] Restrepo AV, Salem JI, Ogusku MM, Gomes LDF, Fraiji NA. Investigation of environmental mycobacteria in tap water, surgical gloves and antiseptic solutions used in surgical procedures at the Getúlio Vargas university hospital, Manaus-AM/Brazil [in Portuguese] Acta Amaz 2009;39:889-900. http://dx.doi.org/10.1590/S0044-59672009000400017.

[119] Sartori FG, Leandro LF, Montanari LB, de Souza MGM, Pires RH, Sato DN, et al. Isolation and identification of environmental mycobacteria in the waters of a hemodialysis center. Curr Microbiol 2013;67:107-11. http://dx.doi.org/ 10.1007/s00284-013-0341-6.

[120] Souza MGM, Sato DN, Leite CQF, Leite SRA, Sartori FG, Prince KA, et al. Occurrence of pathogenic environmental mycobacteria on surfaces in health institutions. Res Rep Trop Med 2010;1:53-8. http://dx.doi.org/10.2147/ RRTM.S13589.

[121] Lerat I, Cambau E, Roth Dit Bettoni R, Gaillard J-L, Jarlier V, Truffot C, et al. In vivo evaluation of antibiotic activity against Mycobacterium abscessus. J Infect Dis 2013;209:905-12. http://dx.doi.org/10.1093/infdis/jit614.
[122] Lounis N, Gevers T, Van Den Berg J, Vranckx L, Andries K. ATP synthase inhibition of Mycobacterium avium is not bactericidal. Antimicrob Agents Chemother 2009;53:4927-9. http://dx.doi.org/10.1128/AAC.00689-09.

[123] Zumla AI, Gillespie SH, Hoelscher M, Philips PPJ, Cole ST, Abubakar I, et al. New antituberculosis drugs, regimens, and adjunct therapies: needs, advances, and future prospects. Lancet Infect Dis 2014;14:327-40. http:// dx.doi.org/10.1016/S1473-3099(13)70328-1.

[124] Bento CF, Empadinhas N, Mendes V. Autophagy in the fight against tuberculosis. DNA Cell Biol 2015;34:228-42. http://dx.doi.org/10.1089/ dna.2014.2745.

[125] Jarlier V, Nikaido H. Mycobacterial cell wall: structure and role in natural resistance to antibiotics. FEMS Microbiol Lett 1994;123:11-8.

[126] Rossi ED, Aínsa JA, Riccardi G. Role of mycobacterial efflux transporters in drug resistance: an unresolved question. FEMS Microbiol Rev 2006;30: 36-52. http://dx.doi.org/10.1111/j.1574-6976.2005.00002.x.

[127] Balganesh M, Dinesh N, Sharma S, Kuruppath S, Nair AV, Sharma U. Efflux pumps of Mycobacterium tuberculosis play a significant role in antituberculosis activity of potential drug candidates. Antimicrob Agents Chemother 2012;56:2643-51. http://dx.doi.org/10.1128/AAC.06003-11.

[128] Sandhu P, Akhter Y. The internal gene duplication and interrupted coding sequences in the MmpL genes of Mycobacterium tuberculosis: towards understanding the multidrug transport in an evolutionary perspective. Int $\mathrm{J}$ Med Microbiol 2015. http://dx.doi.org/10.1016/ j.ijmm.2015.03.005.

[129] Da Silva PEA, Palomino JC. Molecular basis and mechanisms of drug resistance in Mycobacterium tuberculosis: classical and new drugs. J Antimicrob Chemother 2011;66:1417-30. http://dx.doi.org/10.1093/jac/ dkr173. 